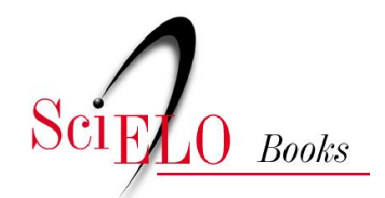

(M) Mackenzie

\title{
A contribuição da FAU-Mackenzie nos concursos de Arquitetura e Urbanismo
}

\author{
Ricardo Carvalho Lima Ramos \\ Daniel Candia Alcantara Oliveira \\ Felipe de S. S. Rodrigues \\ Vinicius da Costa Lopes
}

\section{SciELO Books / SciELO Livros / SciELO Libros}

RAMOS, RCL., et al. A contribuição da FAU-Mackenzie nos concursos de Arquitetura e Urbanismo. In: ALVIM, ATB., ABASCAL, EHS., and ABRUNHOSA, EC., orgs. Arquitetura Mackenzie 100 anos FAU-Mackenzie 70 anos: pionerismo e atualidade [online]. São Paulo: Editora Mackenzie, 2017, pp. 299-326. ISBN 978-85-8293-726-6. Available from: doi: 10.7476/9788582937266. Also available in ePUB from: http://books.scielo.org/id/xrrzx/epub/alvim-9788582937266.epub.

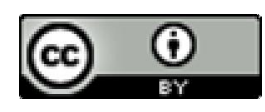

All the contents of this work, except where otherwise noted, is licensed under a Creative Commons Attribution $\underline{4.0 \text { International license. }}$

Todo o conteúdo deste trabalho, exceto quando houver ressalva, é publicado sob a licença Creative Commons Atribição 4.0.

Todo el contenido de esta obra, excepto donde se indique lo contrario, está bajo licencia de la licencia Creative Commons Reconocimento 4.0 . 


\section{A contribuição da FAU-Mackenzie nos concursos de Arquitetura e Urbanismo}

Ricardo Carvalho Lima Ramos, Daniel Candia Alcantara Oliveira, Felipe de S. S. Rodrigues, Vinicius da Costa Lopes
1. Licença poética utilizada por Arquitetos para se referirem à participação da classe profissional em concursos e à grande disposição e importância desses eventos.

\section{Introdução}

Este capítulo apresenta um panorama sintético da participação da Faculdade de Arquitetura e Urbanismo Mackenzie (FAU-Mackenzie) em concursos de Arquitetura e Urbanismo, especialmente na modalidade nacional, procurando expressar o espírito concurseiro ${ }^{1}$ mackenzista. Sem pretender esgotar o assunto, tem o propósito de abrir algumas portas do passado e do presente relativas ao tema. Organiza-se em três partes: a primeira traz uma reflexão sobre a formação do que denominamos "corpo" mackenzista e relaciona um conjunto de concursos importantes vencidos por egressos da FAU-Mackenzie; a segunda apresenta um panorama da participação de docentes e egressos em concursos no século $\mathrm{XXl}$; e a terceira, preocupa-se com o momento de passagem para a condição de profissional, enfatizando o concurso nacional de estudantes de Arquitetura e Urbanismo Opera Prima, que envolve o Trabalho Final de Graduação (TFG).

Como metodologia, adotou-se o critério de abordar projetos vencedores em primeiro lugar ou em posição destacada (que de certa forma privilegiam os jovens Arquitetos recém-formados, mesmo que em segundo ou terceiro lugares) em concursos cujos titulares fossem egressos e/ou docentes da FAU-Mackenzie. Valorizou-se, ainda, o trabalho em equipes e a marca de identidade que aponta para o fato de que o trabalho em parceria, executado por estudantes e professores, bem como por profissionais da área, é prática recorrente na vida dos mackenzistas. Em alguns casos, buscou-se destacar a citação dos jurados nas atas dos concursos, aspecto que auxiliou também a compreender os critérios que contribuíram para a crítica ao projeto indicado ou à própria Arquitetura. Valores como clareza estrutural, apuro técnico, economia de elementos e pouca ou muita valorização do conjunto e da síntese formal (pregnância) são também critérios analíticos de grande relevância, pois balizam o julgamento das obras nos concursos.

O visível êxito dos Arquitetos formados ou que desempenharam atividades profissionais e acadêmicas na FAU-Mackenzie em concursos de Arquitetura, os quais sobre todas as escalas, temas e possibilidades, comprova a sintonia entre concepção e construção, uma tônica arquitetural que permanece. 
2. Optou-se por não incluir imagens dos projetos selecionados, visto que a quantidade de concursos relacionados no capitulo é enorme; a escolha de alguns em detrimento de outros não se justifica.

3. Mesmo não sendo objeto direto deste capitulo, é fundamental ressaltar que o concurso de projetos, no Brasil, vem sendo deixado de lado e seus resultados são muitas vezes desconsiderados nas etapas posteriores que envolvem o projeto executivo e obras. Recentemente, em função das alterações da legislação de licitações (Lei no 8.666 de 1993) e da introdução do Regime de Contratação Diferenciada (RDC), o problema se agrava e alia às sucessivas crises e escândalos políticos ligados às obras de infraestruturas. Considera-se fundamental a valorização dos concursos como etapa inicial de uma importante política pública que pode dar sentido transformador ao projeto e qualificar nossas cidades. As entidades de Arquitetos têm importante papel a cumprir

4. Peter Zumthor: Arquiteto suíço que recebeu em 2009 o Prêmio Pritzker, considerado a maior láurea da área atualmente. Estudou no Pratt Institute em Nova lorque, na década de 1960 Disponível em: <http://www.archdaily. com/tag/peter-zumthor $>$.
O capítulo² não esgota todas as propostas vencedoras em concursos nacionais e estrangeiros que envolveram colegas mackenzistas. Busca resgatar, por meio de alguns exemplos significativos, a relevância da prática para a consolidação de identidade da profissão do Arquiteto e Urbanista, que prima pela formação não apenas individual, mas pelo espírito de cooperação e trabalho coletivo. ${ }^{3}$

\section{Genealogia}

\begin{abstract}
Quando na arquitetura, ocorrem-me imagens. Muitas destas imagens são relacionadas com minha formação e com o meu trabalho como arquiteto. Contêm o conhecimento profissional de arquitetura que pude ganhar no decorrer do tempo. Outras imagens têm a ver com minha infância. Lembro-me desse tempo em que vivia a arquitetura sem pensar sobre isso. Ainda consigo sentir na minha mão a maçaneta do portão, esta peça de metal moldada
\end{abstract} como as costas de uma colher. (ZUMTHOR, 2005, p. 7).

Sempre há um corpo. A ideia em Arquitetura, concebida por quem projeta individual e coletivamente, vem desse corpo. Nas palavras de Zumthor, ${ }^{4}$ a maçaneta evoca o tato, a tecnologia e o momento. A infância traz o tempo corrido e a memória; o trabalho, o ofício. O curso, em processo, une tudo isso pelas reflexões e ações constituídas em cada individualidade criadora.

A formação na FAU-Mackenzie envolve um amplo e complexo contexto de percursos, que inclui um outro corpo: o ser e a história da própria Faculdade. Existe, portanto, uma contaminação positiva entre o edifício da FAU-Mackenzie propriamente, o espaço acadêmico, a estrutura acadêmica, os docentes, os discentes e os egressos. Dessa maneira, a memória extrapola a herança das histórias de vida dos egressos mackenzistas, sendo todo o coletivo da Faculdade formado por uma pluralidade acadêmica, cultural e multidisciplinar. Nesse sentido, é possível afirmar que os concursos de Arquitetura para os estudantes e profissionais sempre tiveram grande relevância na Escola e fizeram com que muitos de seus participantes mackenzistas passassem noites em claro. A FAU-Mackenzie tem tradição em fazer-e-pensar o projeto do edifício à cidade, abundando em participação nas variadas temáticas oferecidas pelos concursos nacionais e internacionais de Arquitetura, Urbanismo e Design.

A contribuição que se apresenta nas respostas projetuais dos concursos é imensa, não só como registro cultural de reflexões em dado momento histórico, mas também como retroalimentação revigorada por visões críticas de futuro para Arquitetura e Urbanismo, no ambiente acadêmico e profissional. É o imaginário identificatório, preconizado por Lucia Santaella e Winfried Nöth (2010, p. 190): sugere-se, pelas propostas projetuais dos concursos, que as imagens e desenhos obtidos em projeção sejam posteriormente transformados em paisagem urbana, moldando a construção da realidade, a percepção dos espaços e indicando os caminhos a trilhar criticamente na construção coletiva das cidades junto à sociedade. 
Os concursos são expressos e comunicados por imagens, desenhos e textos, mas as sínteses gráficas, sobretudo, ocupam papel primordial na revelação de conceitos e da complexidade das reflexões do pensamento por meio dessa linguagem. Nesse sentido, o imaginário identificatório (SANTAELLA; NÖTH, 2010) é interpretado aqui como expressão do eu criativo do Arquiteto e sua visão de cidade. Esse processo é elaborado conforme repertório pregresso e imagens que identificam uma trajetória de pensamento projetual.

Os projetos premiados nos Concursos de Arquitetura são, por assim dizer, expressão de uma visão de sociedade, representada pela comissão julgadora. Essa comissão leva em conta fatores diversos, muitas vezes controversos, representativos de uma gama de interesses presentes no momento, sejam de grupos da elite intelectual, grandes empreiteiras, bancadas políticas, sindicatos, entidades filantrópicas, religiosas etc. Trata-se de relevante amostra da pluralidade, complexidade e conflitos que enfrenta a gestão pública, na tarefa de dar forma ao cotidiano da cidade e às necessidades da sociedade.

As palavras concurso 5 e concorrência provêm do latim correr junto, que traz à memória a ideia de acompanhar, exercer parceria e solidariedade, diferentemente do sentido da palavra inglesa competition, que carrega especificamente o significado de competição (HOUAISS, 2008).

Em 1978, na XX Conferência Geral da Organização das Nações Unidas para a Educação, Ciência e Cultura (Unesco), recomendou-se a todos os países-membros que utilizassem os concursos públicos como modelos adequados de licitação para a realização de projetos de Arquitetura e Urbanismo ${ }^{6}$ (BAETA, 2014). No entanto, a ideia de concurso não é nova. Inúmeros edifícios importantes no mundo, desde o Renascimento, foram objeto de concursos públicos. A União Internacional dos Arquitetos (UIA) defende o concurso público principalmente no contexto da internacionalização da Arquitetura, ocorrida com o movimento moderno. No Brasil, diversas entidades ligadas à profissão de Arquiteto e Urbanista, com destaque para o Instituto dos Arquitetos do Brasil (IAB) e o Conselho de Arquitetura e Urbanismo (CAU) defendem o concurso público como oportunidade fundamental à cidade, em contraposição à defesa exclusiva de interesses privados.

Os concursos possibilitam a manifestação e divulgação de um novo ideário. Daí a grande relevância teórica dos memoriais e partidos arquitetônicos propostos, o que evidencia uma excepcional e cativante possibilidade para a revelação de novos talentos e novas tecnologias, para o surgimento de temáticas inovadoras e para a intensificação da atuação dos Arquitetos (FIALHO, 2001, p. 6).

Com relação à atuação dos mackenzistas, verifica-se a presença de uma rede profissional que qualifica Arquitetos de perfil concurseiro, o que pode ser constatado nas diversas gerações formadas até hoje. São muitas as menções às parcerias estudantis e profissionais de egressos e docentes do Mackenzie, em concursos e atividades projetuais (FERRONI, 2010). Antes de adentrar propriamente o panorama dos concursos de que participaram essas
5. No Diccionario Metápolis Arquitectura Avanzada (GAUSA, 2000, p. 124), o autor propõe uma definição de concurso na qual os que realmente estão em julgamento são os jurados.

6.. A Unesco, pela XX Conferência Geral, de 1978, da qual o Brasil é signatário, recomenda aos países membros a adoção do concurso de projeto segundo normas e princípios que indica - júri técnico; contratação do vencedor para desenvolver o projeto; garantia dos direitos de autor. Após tal recomendação, a Lei nº 8.666 de 1993 adotou o concurso como modalidade de licitação para "serviços técnicos profissionais especializados" (MAGALHÃES, 2016). 


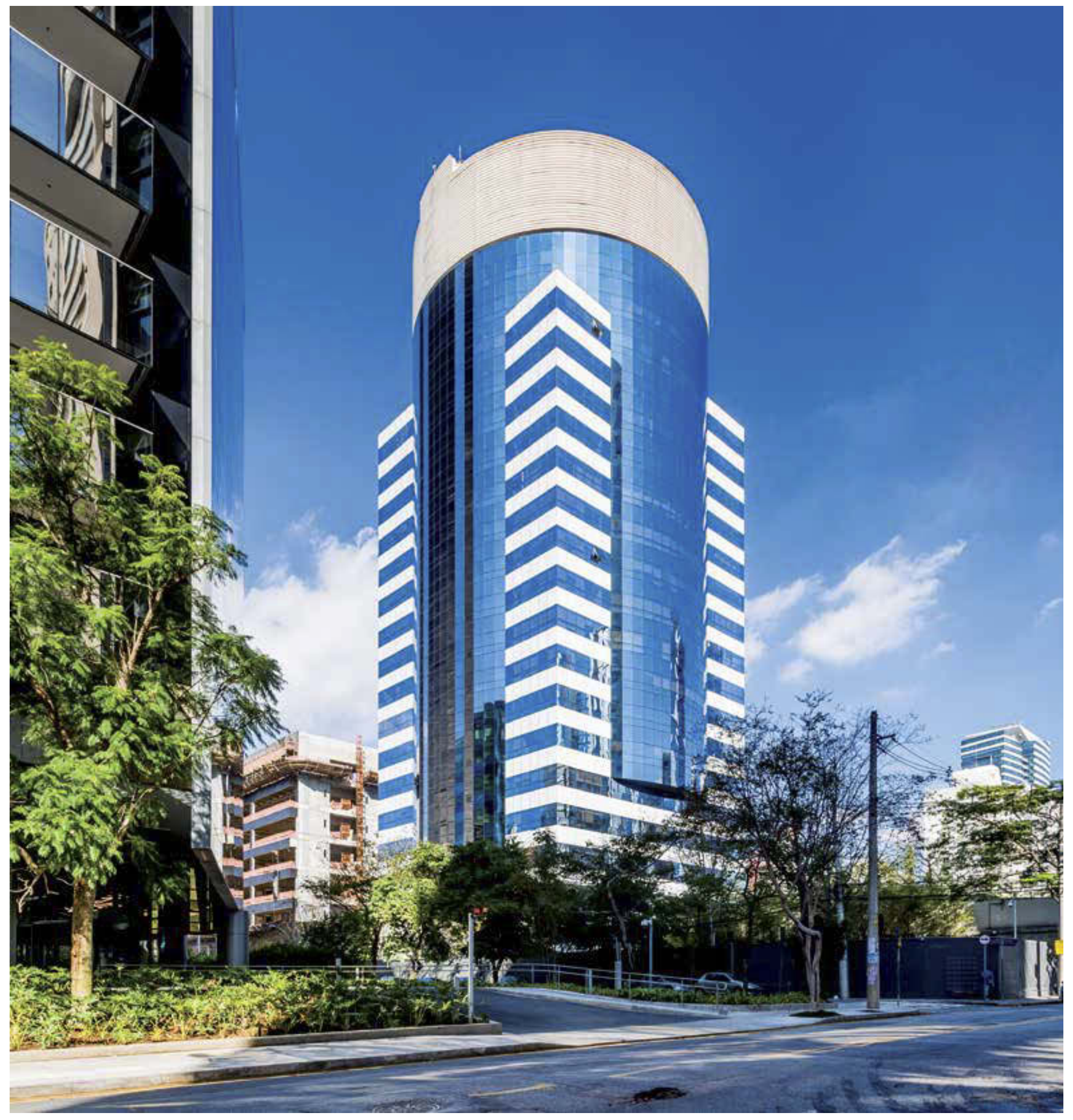


primeiras gerações formadas no Mackenzie, o editorial do Arquiteto Pedro Paulo de Melo Saraiva (1933-2016) escrito para a Revista Se... especial sobre concursos traz uma visão histórica e revela o espírito de parceria e trabalho coletivo presente à época, o qual se tornaria marca entre mackenzistas dessas gerações (REVISTA SE..., 2001, p. 1):

À guisa de Editorial

Concurso de Arquitetura - maneira de escolher um projeto ou um arquiteto

A questão nos remete, talvez, ao fim da Idade Média, ao renascimento. Desde então concursos de arquitetura tem sido uma maneira de escolha de um projeto ou um arquiteto.

Entre nós, nos anos 50, Rino Levi defendia a tese de que num concurso se escolhe o arquiteto, e não o projeto. A verdade é que naquela época Rino Levi já era um arquiteto consagrado! Nós, jovens arquitetos, víamos nos concursos uma forma de afirmação e desta prática alguns de nós surgimos do anonimato. Dos anos 60 aos 70, jovens como Rubens $C$. Viana, Adolfo R. Morales, Paulo M. da Rocha, Alfredo S. Paesani, Ricardo Sievers, Julio Neves, Julio Katinsky, Ruy Ohtake, Mauricio Tuck Schneider, Carlos Millan, Jorge Wilheim, Abrahão Sanowicz e eu próprio, só para falar os de São Paulo, destacaram-se profissionalmente principalmente através de concursos públicos ou privados.

Naquela época, é bom salientar, Lúcio Costa venceu o concurso do Plano Piloto de Brasília em certame público, em que os participantes assinavam seus projetos (eu inclusive) $\mathrm{O}$ anonimato era uma reivindicação geral, pois além de eticamente desejável, era uma forma de proteger o corpo de jurados da inevitável pressão e "peso" dos nomes consagrados. Não foi evidentemente o caso do concurso em que Lúcio Costa venceu; houve aqui a infeliz postura de Paulo Antunes Ribeiro (um dos membros do júri), que em voto separado pretendia fazer uma comissão de cerca de seis concorrentes (não de seis arquitetos!) para fazer Brasília.

Depois de uma época promissora, em que jovens arquitetos surgiram no cenário profissional, o sonho de desvaneceu. Não eram raros os arquitetos que discordavam desta forma de acesso aos trabalhos. Alguns viam nos concursos um meio de exploração de nosso trabalho por considera-los aviltantes e pouco significativos em termos culturais.

O fato real é que o anonimato continuou a prevalecer ainda que, em certos casos, o desenho e certos "tiques" (escrever o memorial a mão, p. ex.) entregavam a autoria do projeto, e então...

Essa prática foi coibida veementemente no concurso do Centre Beauburg (Museu Georges Pompidou) em que foi limitada a um metro quadrado a prancha de cada concorrente, exigindo-se padronização total na apresentação. Hoje, o computador acabou por "pasteurizar" todas as apresentações.

Os tempos do concurso do Pavilhão L'Orloge (Louvre) em que ocorreram Lourenzo Bernini e François Blondel já vão longe. Ninguém na época supunha que o autor da colunata de São Pedro perderia para o autor da fórmula do passo das escadas $(2 e+p)$.
Na página anterior:

Centro Empresarial e Cultural João Domingues de Araújo (IDA), São Paulo, 2005. Projeto do Arquiteto Carlos Bratke (Mackenzie, 1967). 
Como naquela época, às vezes os concursos surpreendem, mas não colocam em cheque a democrática forma ancestral de escolha do arquiteto, mas sim um júri que assuma coletivamente uma postura crítica em relação à nossa produção arquitetônica, isto é, a arquitetura que interessa à nossa cultura, que invoque nosso passado e que insinue nosso futuro. Episódios lamentáveis ocorridos em concursos recentes só poderão ser sanados na medida em que os membros dos júris forem compostos a partir de critérios transparentes, livres de modismos e personalismos deletérios, com uma postura que reconheça nossos valores e nossa história.

De qualquer modo, os concursos de Arquitetura têm servido como fenômeno elucidador do estágio de desenvolvimento da profissão, pois, pelo número sempre expressivo de participantes, temos um quadro dinâmico capaz de identificar tendências e apontar caminhos.

No amplo contexto de sua formação, o Arquiteto Pedro Paulo de Melo Saraiva (Mackenzie, 1955) demonstra ter convivido e atuado em parceria na Faculdade com outros colegas e contemporâneos que se tornariam destacados Arquitetos: Alberto Botti (Mackenzie, 1954), Alfredo Paesani (Mackenzie, 1954), Carlos Barjas Millan (Mackenzie, 1951), Fábio Penteado (Mackenzie, 1953), João Kon (Mackenzie, 1955), José Maria Gandolfi (Mackenzie, 1958), Júlio Neves (Mackenzie, 1954), João Eduardo de Gennaro (Mackenzie, 1954), Jorge Wilheim (Mackenzie, 1952), Luiz Forte Netto (Mackenzie, 1958), Marc Rubin (Mackenzie, 1955), Francisco Petracco (Mackenzie, 1958), Maurício Tuck Schneider (Mackenzie, 1956), Paulo Mendes da Rocha (Mackenzie, 1954), Roberto Aflalo (Mackenzie, 1950), entre outros (GIMENEZ, 2016, p. 21). A reflexão sobre os concursos de Arquitetura compõe um ideário que permite não só destacar a efetiva produção do corpo discente e docente da FAU-Mackenzie e sua genealogia no século XX, mas também revelar a grande contribuição social prestada, fato que pode ser verificado por alguns importantes concursos, realizados entre os anos 1950 e 2000, em que Arquitetos mackenzistas ganharam o primeiro lugar: São eles:

- Palácio da Assembleia Legislativa do Estado de Santa Catarina, 1957. Pedro Paulo de Melo Saraiva, Paulo Mendes da Rocha e Alfredo Paesani (10 lugar).

- Ginásio do Club Athletico Paulistano, 1958. Paulo Mendes da Rocha e João Eduardo de Gennaro (10 lugar).

- Sede Social do Clube XV de Santos, 1963. Francisco Petracco e Pedro Paulo de Melo Saraiva (10 lugar)

- Salão de Festas do Clube Sírio, 1966. Pedro Paulo de Melo Saraiva, Miguel Juliano e Sami Bussab (10 lugar).

- Palácio da Justiça do Estado de Santa Catarina e Fórum de Florianópolis, 1966 Francisco Petracco, Pedro Paulo de Melo Saraiva e Sami Bussab (10 lugar). 
- Monumento aos Mortos do Atlântico Sul, 1968. Flávio Marcondes, Vasco de Mello e Luiz Gonzaga de Oliveira Camargo (10 lugar).

- Escola de Administração Fazendária, 1973. Pedro Paulo de Melo Saraiva, Mayumi de Souza Lima e Sérgio Ficher (10 lugar).

- Reurbanização do Vale do Anhangabaú, 1981. Jorge Wilheim e Rosa Kliass (10 lugar).

- Museu Brasileiro da Escultura, 1988. Paulo Mendes da Rocha (10 lugar).

- $\quad$ Avenida Paulista, 1996. José Magalhães Jr. e José Francisco Xavier Magalhães. (10 lugar).

- Concurso Nacional de Ideias para um Novo Centro de São Paulo, 1997. Equipe multidisciplinar, que inclui: João Batista Martinez Corrêa (Mackenzie, 1968), José Paulo de Bem, Roberto Righi, Ronan Ayer, Ernesto Zamboni, Flávio Pastore, Marcelo Fragelli, Sérgio Coelho, Hércules Fidalli, Luiz Eduardo Sózio, Renato Mendonça, Shigeru Yamamoto, Cláudio de Mattos Falcão, Leonardo Lorenzo, Edison Borges Lopes, Cássio Norio Hosomi, Maria Luíza Oieno de Oliveira, Rita Guimarães, Walter Maximiliam Gosslar, Alessandra Gizella da Silva, Francisco Denon e Mauro Lima.

- Reurbanização de Ilhabela, 1998. José Magalhães Jr. (Mackenzie, 1965) e José Francisco Xavier Magalhães (Mackenzie, 1988) (10 lugar).

\section{A participação de docentes e egressos da FAU-Mackenzie em concursos a partir dos anos 2000}

É possível dizer que, a partir dos anos 2000, os concursos de Arquitetura explicitaram, por meio de muitas propostas vencedoras, maneiras de abordagem e de julgamento que já vinham sendo transformadas no decênio anterior, e proposições puderam se tornar exercícios de síntese. Nos concursos públicos, as propostas têm em comum a valorização do rigor estrutural, sem tanta ênfase nos elementos formais; em concursos particulares, a experimentação formal é grandemente valorizada, enfatizando-se a formulação de novas espacialidades.

Ainda no final da década de 1990, o Concurso Nacional de Ideias para Revitalização das Marginais Pinheiros e Tietê - São Paulo/SP, realizado pelo IAB/SP em parceria com a Prefeitura Municipal de São Paulo, inaugura o início do século XXI, classificando egressos e docentes da FAU-Mackenzie em segundo e terceiro lugares, a saber: $2^{\circ}$ colocados - Arquiteto Francisco Spadoni e Arquiteto Carlos Leite (docentes da FAU-Mackenzie); $3^{a}$ colocadas Arquiteta Maria Elena Merege Vieira (Mackenzie, 1962), Arquiteta Pérola Felipette Broncaneli (Mackenzie, 1992) e Arquiteta Maria Silvia Merege Vieira. 


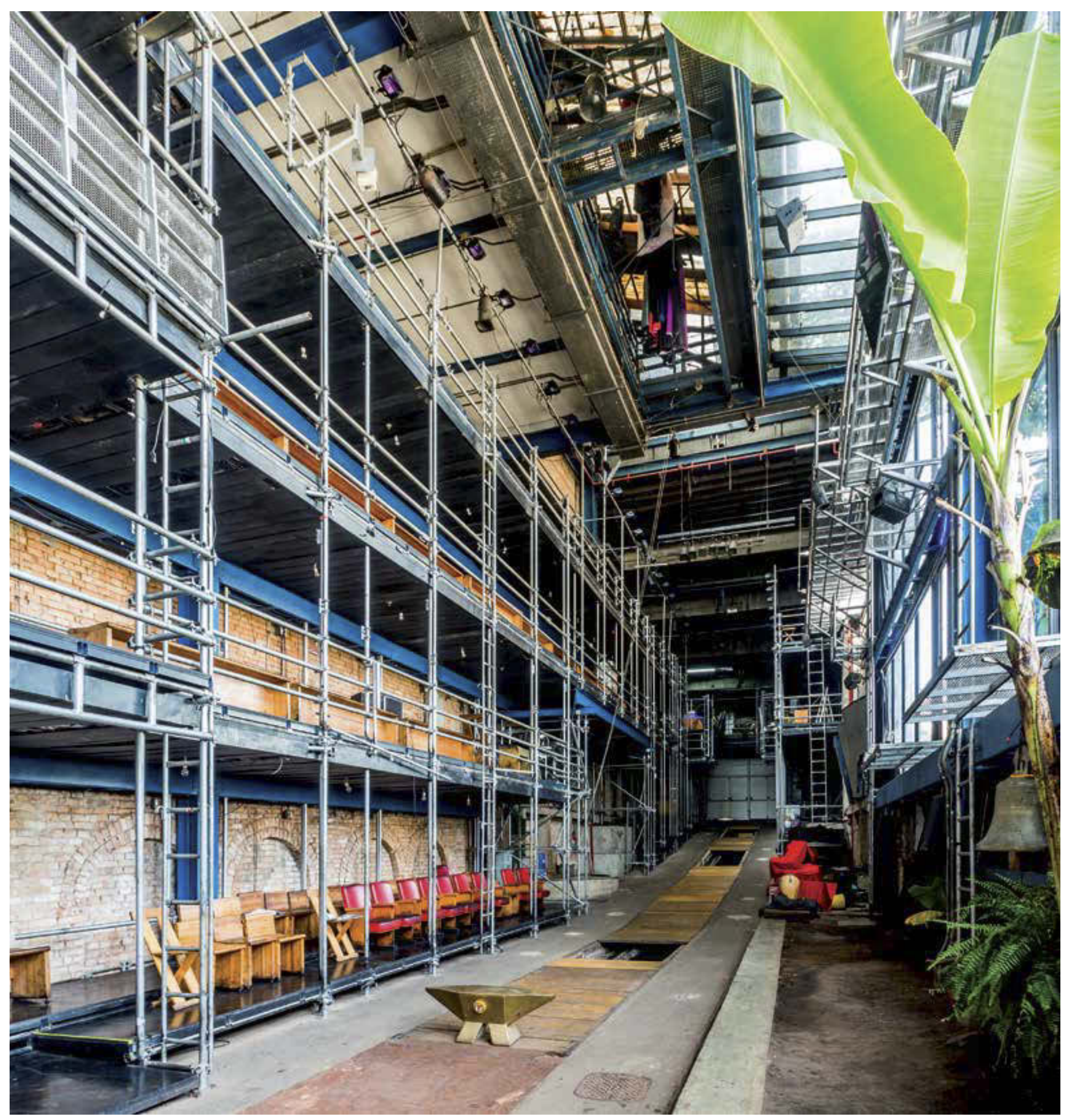


Possivelmente, o primeiro concurso de maior repercussão do início da década de 2000 tenha sido o Concurso Público Nacional Reconversão Urbana do Largo da Batata, em 2002 (CONCURSO PÚBLICO NACIONAL, 2002), ${ }^{7}$ organizado pela Prefeitura de São Paulo e o IAB-SP. A equipe ${ }^{8}$ de Tito Livio Frascino (Mackenzie, 1964) conquistou o primeiro lugar ao apresentar proposta de requalificação urbana. A leitura apropriada das esferas local e metropolitana, dos antecedentes históricos e, ao mesmo tempo, uma visão de futuro para a cidade conferida pelo projeto, valorizando as singularidades, levou à premiação.

Em 2004, outro relevante certame vencido por mackenzistas que merece menção foi o Concurso Público de Arquitetura para o Aeroporto Internacional de Florianópolis, organizado pela Empresa Brasileira de Infraestrutura Aeroportuária (Infraero) e IAB-DF. Na competição, as duas equipes finalistas, ${ }^{9}$ a primeira de Mario Biselli (Mackenzie, 1985) e Artur Katchborian (Mackenzie, 1985), e a segunda, de Marcelo Barbosa (Mackenzie, 1984), disputavam o certame. Naquele momento, o programa aeroportuário não constava da experiência de Biselli e Katchborian, contando com o mérito de ficar entre os finalistas (FINALISTAS DO AEROPORTO, 2004). A inexperiência no desenvolvimento do programa não foi impedimento para que fosse reconhecido o mérito da proposta - nesta, a qualidade formal não foi constrangida pela magnitude das soluções técnicas utilizadas no projeto. À dupla e à sua equipe ${ }^{10}$ foi concedido o primeiro prêmio, com destaque para a apreciação da comissão julgadora, que sintetiza a conquista: "Este projeto destacou-se pela integração entre forma e função, do qual resultou uma concepção simples e integrada à paisagem" (CONCURSO PÚBLICO, 2002, p. 1). ${ }^{11}$

Ainda em 2004 é lançado o Concurso Bairro Novo, organizado pelo IAB/SP em parceria com a Prefeitura de São Paulo, cujo desafio era a elaboração de projeto urbano para um bairro inteiro de uso predominantemente residencial. O bairro escolhido para a proposta foi a Água Branca, uma área com aproximadamente 1 milhão de metros quadrados (RAMOS, 2010, p. 13). Pode-se dizer que no concurso houve uma conjunção de mackenzistas, uma vez que o segundo e o terceiro lugares foram concedidos a equipes formadas por vários Arquitetos atuantes no Mackenzie, egressos, professores e estudantes. $O$ trabalho apresentado pela equipe formada por José Paulo de Bem, Joan Villà (Mackenzie, 1968) e Luiz Guilherme Rivera de Castro, professores da FAU-Mackenzie, ganhou o segundo lugar e recebeu o seguinte comentário do júri: "Boa integração viária com o entorno, bom traçado viário dando unidade ao bairro, havendo indicações claras para a composição volumétrica das quadras" (CONCURSO BAIRRO, 2004).

Francisco Spadoni e Lauresto Esher (Mackenzie, 1967), também professores da casa, e agraciados com o terceiro lugar, atribuem o título "Conceito: recomposição e centralidade" ao projeto premiado (CONCURSO BAIRRO, 2004). Definem o projeto como uma proposta para um dos grandes vazios da cidade de São Paulo, o qual, junto a uma densa urbanidade, requer um complexo programa de atividades composto "por um desenho ordenador que assuma as estruturas existentes dando-Ihes novos sentidos e as complemente com novas matrizes de organização territorial" (CONCURSO BAIRRO, 2004).
Na página anterior:

Teatro Oficina, São Paulo, 1989. Projeto da Arquiteta Lina Bo Bardi (Faculdade de Arquitetura da Universidade de Roma 1939) e do Arquiteto Edson Jorge Elito (Mackenzie, 1971).

7. O primeiro grande certame da virada do século foi o concurso fechado e internacional para o novo Museu de Arte Contemporânea da Universidade de São Paulo (MAC-USP), que contou com a proposta do Arquiteto Paulo Mendes da Rocha (Mackenzie, 1954). Também concorreram os Arquitetos Arata Isozaki, Eduardo de Almeida e Bernard Tschumi, o vencedor do concurso.

8. A equipe vencedora foi composta por Tito Livio Frascino (Mackenzie, 1964), Rosa Ribeiro, Leticia Lodi, Alexandre Stefani, Andrea Soares e Rosa Maria Leal.

9. Também era finalista a equipe de Sérgio Roberto Parada, Arquiteto especialista em aeroportos.

10. Equipe formada por Mario Biselli (Mackenzie, 1985), Guilherme Motta, Orlando Pudenzi, Cristiana Rodrigues, Daniel Corsi da Silva (Mackenzie, 2003) Artur Katchborian (Mackenzie, 1985). Colaboraram também Sérgio Matera, Laura Paes Barretto Pardo, Ana Carolina Pudenzi (Mackenzie, 2001), Tais Cristina da Silva (Mackenzie, 2004), Andre Biselli Sauaia (Mackenzie, 2006) e Victor da Paixão (Mackenzie, 2006).

11. Segundo colocado: equipe formada pelos Arquitetos Jaime M. Cupertino, José Paulo de Bem, Joan Villà

(Mackenzie, 1968), Luis Guilherme R. Castro, Silvia Chile (Mackenzie, 1998) e Maria Augusta Bueno (Mackenzie, 1998), terceiro colocado: equipe formada por Francisco Spadoni, Lauresto Esher (Mackenzie, 1967), Selma Bosquê e Tiago Andrade. 
12. Também colaboraram Christian Michael Seegerer,

Cristiane Tashiro (Mackenzie, 2000), Daniel Fonseca (Mackenzie, 2002),

Érika Engels (Mackenzie, 2006),

Fabiana Lima (Mackenzie, 2009)

e Yuri Vital (Mackenzie, 2004).

13. Completam a equipe: Júlio César Corbucci, Ana Cecília Parente (Mackenzie, 2003), Carlos Rivera, Fabio Mosaner, Heralcir Cesari (Mackenzie, 1994)، Luiz Fernando Farkas, Sophia Telles, Laura Elisa Poggio (Mackenzie, 2005) e Sarah Mota (Mackenzie, 2006).

14. Arquitectum é a mais antiga plataforma internacional de competições de Arquitetura do seu tipo, focada na organização de competições e eventos cobrindo uma gama de projetos promocionais, conceituais e profissionais.
Em outro estado no mesmo ano, no Concurso Público Nacional de Arquitetura Sede da Procuradoria Regional da República da $4^{a}$ Região, organizado pelo IAB-RS (CONCURSO PÚBLICO NACIONAL, 2004), destacaram-se entre Arquitetos de grande experiência, como Candi Hirano (Mackenzie, 1968; então docente da FAU-Mackenzie), os recém-formados Daniel Corsi (Mackenzie, 2003) e Dani Hirano, egressos em 1999.12 O quinto lugar foi um reconhecimento inicial importante para aquilo que viria a ser apenas ponto de partida para os próximos certames. Sobre a proposta, o júri levanta relevantes questões e acentua que "A funcionalidade e economicidade são efetivamente atributos que [...] o qualificam" (CONCURSO PÚBLICO, 2004).

O terceiro lugar atribuído à equipe de Marcelo Barbosa (Mackenzie,1984) $)^{13}$ no Concurso para a Sede da Petrobras em Vitória, organizado pelo IAB-ES em 2005 (SEDE DA PETROBRAS, 2005), evoca perenidade em vez de contrariedade. A constância com que alguns desses personagens participam de competições é justamente o elemento motivador que tem influenciado as gerações seguintes. No certame, a ata qualifica a proposta ao mesmo tempo em que reforça os parâmetros regentes da Arquitetura dessa década: "a correta e baixa ocupação do terreno, assim como a concisa solução do programa de necessidades, a excelente solução do estacionamento coberto e a simplicidade prevista para a ampliação futura" (SEDE DA PETROBRAS, 2005).

A expressiva participação dos mackenzistas em concursos não deixa de ser reflexo da construção de um repertório coletivo, a partir da colaboração de alunos com seus mestres; não à toa, muitos desses profissionais também lecionam na instituição que um dia lhes conferiu o título de Arquiteto. Por vezes, esses jovens Arquitetos se sentem confortáveis e vão além, apostando em concursos internacionais, quando então a língua poderia ser uma barreira. Em 2005, os contemporâneos de formação Daniel Corsi, Victor da Paixão (Mackenzie, 2006), André Sauaia (Mackenzie, 2007), Reinaldo Nishimura (Mackenzie, 2006) e Daniel Fonseca (Mackenzie, 2002), foram agraciados com o segundo lugar no $1^{\circ}$ International Competition Global House for Young Architects (10 INTERNATIONAL, 2006), organizado pela plataforma Arquitectum, ${ }^{14}$ com o tema "A Casa para o Mundo Globalizado do Século 21", selecionados entre 250 trabalhos e 400 Arquitetos (BRASILEIROS SE DESTACAM, 2006).

Outras vezes, não são tão explícitas essas colaborações. No Concurso Público Nacional de Arquitetura para o Teatro de Natal, ocorrido em 2005 e organizado pelo governo do Rio Grande do Norte (TEATRO DE NATAL, 2010), o IAB-RN e a Fundação José Augusto, a equipe de Mario Biselli e Guilherme Motta conquistou o primeiro prêmio (SEGUNDO COBERTURA, 2006), com os colaboradores Daniel Corsi, Tais Cristina da Silva (Mackenzie, 2004), Renata Castanho (Mackenzie, 2008), André Sauaia, Fernanda Castilho (Mackenzie, 2005), Victor da Paixão, Marcela Ernani (Mackenzie, 2007), egressos no primeiro decênio do século XXI e quase todos colaboradores em certames anteriores. Em meio a tantos trabalhos de qualidade similar, a proposta vencedora, segundo os jurados, distinguiu-se, malgrado terem notado sua solução formal simples, como um edifício expressivo, uma Arquitetura referencial para a cidade (SEGUNDO COBERTURA, 2006). 
No começo de 2006 foi divulgado o resultado do Concurso Público Nacional de Projeto de Arquitetura para o campus da Universidade Federal do $A B C$ (UFABC), organizado pelo IAB-DN, o que configurou uma rara oportunidade de projetar um campus universitário de acordo com as demandas contemporâneas. Conquistaram o primeiro prêmio Claudio Libeskind, Sandra Llovet, David Ruscalleda e Mario Lotfi, este formado pelo Mackenzie em $2005 .{ }^{15}$ Segundo o júri, a criação de praças na parte frontal da área, na Avenida dos Estados e a forte imagem urbana foram decisivos para a escolha (NOVA FACHADA, 2006).

No mesmo ano, no Concurso Público Nacional de Anteprojetos de Arquitetura do Centro Judiciário de Curitiba, organizado pelo IAB-PR e pela municipalidade, as equipes de Mario Biselli e de Jorge Königsberger (Mackenzie, 1971) obtiveram o primeiro prêmio. Segundo o memorial elaborado pelos autores, o projeto apresenta uma grande unidade, que se expressa em vários de seus elementos, de forma criativa e inovadora: partido arquitetônico, detalhes construtivos, funcionalidade, plástica, inovações tecnológicas e elementos de conforto ambiental voltados à sustentabilidade (CONCURSO NACIONAL CENTRO, 2006).

Em 2007, uma descrição aproximada pôde caracterizar a proposta de Mário Biselli e parceiros, os jovens Arquitetos Dani Hirano e Daniel Corsi, no Concurso Público Nacional de Estudo Preliminar de Arquitetura para a Sede da Capes - Brasília, DF. No certame, a equipe garantiu o terceiro lugar (CONCURSO NACIONAL CENTRO, 2006).

No Concurso Público Nacional de Arquitetura para o Teatro Municipal de Londrina (CONCURSO PÚBLICO NACIONAL, 2007), organizado pelo IAB-PR e a municipalidade, conquistou o primeiro prêmio o grupo de Arquitetos egressos do início dos anos 2000: André Luque (Mackenzie, 2011), Thiago Nieves (Mackenzie, 2002), Pablo Leite Chakur (Mackenzie, 2001), Amauri Sakakibara (Mackenzie, 2001) e Fernanda Ferreira (Mackenzie, 1999). ${ }^{16}$ Embora a vitória desses jovens tivesse causado certa euforia, sua experiência em concursos não era novidade; todos já haviam participado como estudantes ou Arquitetos em certames anteriores. Segundo o júri, o projeto vencedor apresenta uma simplicidade construtiva, e não exige soluções dispendiosas para sua realização. Atende às exigências do programa sem recorrer a virtuosismos formais (CONCURSO PÚBLICO NACIONAL, 2007).

No Concurso Nacional de Arquitetura para o Complexo Trabalhista do Tribunal Regional do Trabalho (TRT) de Goiânia, organizado pelo IAB-GO em 2007, os Arquitetos Daniel Corsi, Dani Hirano e Reinaldo Nishimura ${ }^{17}$ (Mackenzie, 2006) obtiveram reconhecimento profissional com o resultado satisfatório - a primeira colocação garantiu-lhes os meios necessários para abrirem escritório próprio -, o que é recorrente, e motivo pelo qual é uma constante a participação de jovens Arquitetos em concursos. Nesses dois últimos concursos mencionados, é significativo que seus mestres também foram premiados nas demais posições. É o caso dos veteranos Mario Biselli e Artur Katchborian (ambos Mackenzie, 1985), Lílian Dal Pian e Renato Dal Pian, Lucas Fehr, Mario Figueroa, Paulo Henrique Paranhos, Carlos Alberto Maciel, entre outros. Sucessivas gerações em que mestres legam seus conhecimentos aos discentes comprovam prodigiosa tradição, fruto de completa compreensão das características das competições de natureza pública e da expertise dos participantes.
15. Também colaboraram no projeto: Cristiana Rodrigues, Carolina Dal Ben, Claudia Filardo, Gabriel Bicudo e Alexandre Nobre.

16. Fernanda Ferreira (Mackenzie, 2004) e Pablo Leite Chakur (Mackenzie, 2001) colaboraram por anos com Lilian e Renato Dal Pian, conhecidos por suas participações e vitórias em concursos: Ferreira, de 1996 a 2001; e Chakur, de 2001 a 2006.

17. Também colaboraram nesta equipe Liana Perez Oliveira (Mackenzie, 1999) e Laura Paes Barreto Pardo. 
Sala São Paulo, 1938 (revitalização

realizada em 1999). Projeto original do

Arquiteto Christiano Stockler das Neves,

fundador do Curso de Arquitetura da

Universidade Mackenzie; reforma e

reciclagem de uso do Arquiteto Nelson

Dupré (Mackenzie, 1973).

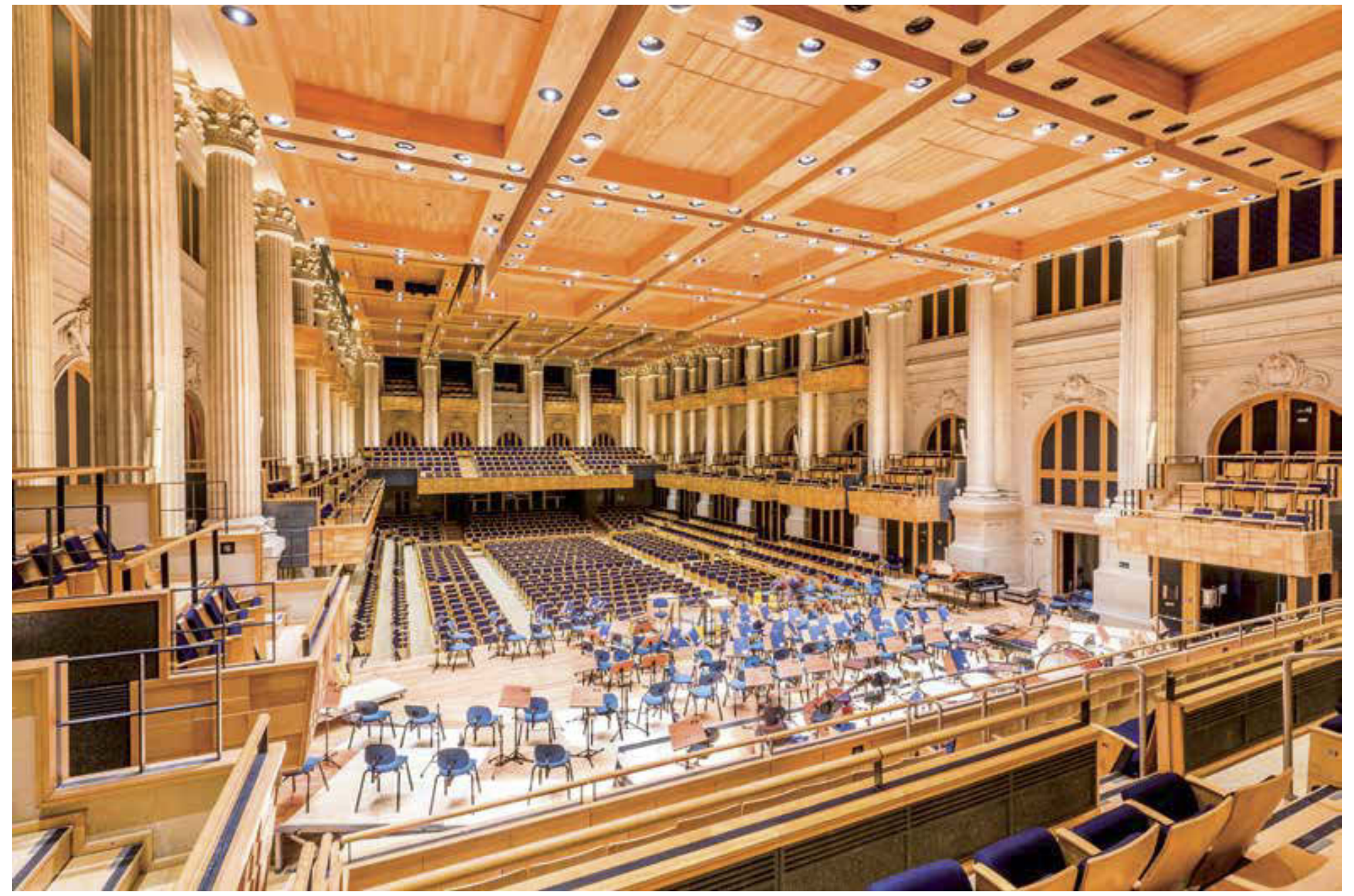


Em 2009, no Concurso de Propostas Arquitetônicas para o futuro Sesc Guarulhos, organizado pelo Sesc-SP, os Arquitetos Mario Biselli e Artur Katchborian e sua equipe ${ }^{18}$ garantiram a segunda posição. De acordo com os Arquitetos, o projeto definiu um eixo que liga a rua e o parque, determinando as melhores condições de implantação e eixos de distribuição para articular suas múltiplas funções (SESC GUARULHOS, 2010).

No Concurso Público Nacional de Anteprojetos de Arquitetura e Complementares para a Requalificação e Ampliação do Complexo Teatro Castro Alves, realizado pelo IAB-BA em 2010, a equipe ${ }^{19}$ dos Arquitetos e docentes da FAU-Mackenzie - Lucas Fehr, Mario Figueroa, Guilherme Motta, Carlos Eduardo Garcia (Mackenzie, 2008) e Marcus Vinícius Damon (Mackenzie, 2008) - conquistou o primeiro lugar. Embora Motta, Fehr e Figueroa tenham se graduado em outras instituições, sua atuação na FAU-Mackenzie é significativa. ${ }^{20}$

Após extensa deliberação, a ata do júri salienta que o projeto se singulariza pela inserção harmoniosa no sítio, o que propiciou uma volumetria inovadora, eminentemente horizontal que valoriza o TCA (SESC GUARULHOS, 2010). Vale mencionar que os Arquitetos Lucas Fehr, Mario Figueroa e Carlos Dias ${ }^{21}$ ganharam o primeiro prêmio, em 2007, no Concurso de Arquitectura Centro Matucana - Museo de la Memoria, organizado pelo Ministério de Obras Públicas do Chile (MELENDEZ, 2010). A equipe ${ }^{22}$ se sairia vitoriosa também no Concurso Público Nacional Complexo Hotel Paineiras - Parque Nacional da Tijuca em 2009, organizado pelo IAB-RJ e no Concurso Nacional de Arquitetura Ponte e Passarela em Blumenau, organizado pelo IAB-SC em 2011. ${ }^{23}$

Concursos organizados pelo IAB para requalificação de áreas centrais tiveram Arquitetos mackenzistas entre os primeiros colocados. No Concurso Nacional de Ideias para Requalificação de Largos no Pelourinho (CONCURSOS PÚBLICO NACIONAL, 2011) organizado pelo IAB-BA em 2011, a equipe ${ }^{24}$ de Arthur de Mattos Casas (Mackenzie, 1983) conquistou o primeiro lugar. As seguintes qualidades foram atribuídas ao projeto pelo júri: "Compreensão crítica da função histórica dessas áreas centrais, diversidade e flexibilização dos usos" (A BAIANIDADE, 2012, p. 28). Do mesmo modo, os egressos de 2006 Rafael Neves e Beatriz Martinhão conquistaram a segunda posição ${ }^{25}$ no Concurso Público Nacional do Paço Municipal de Várzea Paulista (PREMIADOS - CONCURSO PAÇO, 2012), organizado pelo IAB-SP em 2012.

Ainda em 2011, e fechando o ano com chave de ouro, a proposta da equipe formada por docentes da FAU-Mackenzie vence o concurso As Cidades Somos Nós - Propostas para a São Paulo de 2030. José Paulo de Bem, Cassia Regina Mariano, professores da FAU- Mackenzie, e Fernanda de Macedo Haddad apresentam projeto para uma intervenção na Praça da Bandeira e ampliações de suas conexões com o Largo São Francisco, Praça do Patriarca e Câmara Municipal, abrangendo um raio de 500 metros a partir do terminal de ônibus existente. O concurso tinha por objetivo contribuir, por meio de soluções criativas, com as políticas de planejamento urbano e para o futuro das cidades (CONCURSO "A CIDADE", 2011):
18. Equipe: Arquitetos Ana Carolina Ferreira Mendes (Mackenzie, 2007) André Biselli Sauaia, Cassia Lopes Moral (Mackenzie, 2007), Cassio Oba Osanai (Mackenzie, 2007), Daniel Corsi, Dani Hirano, Luiz Marino Küller e Reinaldo Nishimura; estagiários: Claudia Zanoio (Mackenzie, 2010), Luciana Conti (Mackenzie, 2009) e Raquel Rodorigo (Mackenzie, 2009)

19. Colaboradores: Arquitetos Luciana Brasil (Mackenzie, 1996), Naiara Hirota (Mackenzie, 2008) e Vicente Deeke Boguszewiski; estagiários: Amanda Renz (Mackenzie, 2010), Mário do Val (Mackenzie, 2010), Juliana Baldocchi (Mackenzie, 2010), Kalina Juzwiak (Mackenzie, 2010), Luisa Monserrat, Renata Santoniero (Mackenzie, 2011) e Tiago Collet (Mackenzie, 1995)

20. Motta leciona desde 1993 na FAU-Mackenzie, Figueroa lecionou de 1993 a 2014, e Fehr leciona desde 2000 atualmente é coordenador do Curso.

21. Colaboradores: Amanda Renz, Carlos Eduardo Garcia, Flávia Tenan (Mackenzie, 2010), Josei Nagayassu (Mackenzie, 2009), Juliana Baldocchi, Juliana Klein (Mackenzie, 2008), Marcus Vinícius Damon (Mackenzie, 2008) e Marina Canhadas.

22. Autores: Carlos Garcia, Guilherme Lemke Motta, Lucas Fehr, Marcus Vinicius Damon, Mario Figueroa; colaboradores: Amanda Renz, Christián Ribeiro, Juliana Baldocchi, Kalina Juzwiak, Luiza Monserrat, Mario do Val, Pedro Lindenberg e Tiago Collet.

23. Autores: Carlos Garcia, Guilherme Motta, Lucas Fehr, Marcus Vinicius Damon, Mario Figueroa, Mario do Val, Ricardo Dias; colaboradores: Amanda Renz, Ana Maria Montag (Mackenzie, 2006), Fabio Ucella (Mackenzie, 2008), Luciana Brasil, Vicente Boguszewski e Mariana Matarazzo.

24. Também são coautores: Azevedo França, Joana Garcia de Oliveira, Gabriel de Andrade Ranieri (Mackenzie, 2011), Regiane Khristian Silva Bouças (Mackenzie, 2002), Rodrigo da Costa Tamburus (Mackenzie, 2012) e Mariana Pianta Santoro (Mackenzie, 2012). 
25. No "Concurso 'A Cidade Somos Nós - Propostas para a São Paulo de 2030' contempla 6 trabalhos", de um total de 106 inscritos, a comissão julgadora selecionou seis trabalhos que deveriam contemplar uma visão da área em um horizonte de 20 anos, abordando os aspectos de desenvolvimento e mobilidade urbana que têm como base os "10 Princípios da Mobilidade Urbana Sustentável" (CONCURSO "A CIDADE", 2011).

26. Trabalharam na proposta: Pedro Paulo de Melo Saraiva (Mackenzie, 1955) Fernando de Magalhães (Mackenzie 1996), Pedro de Melo Saraiva (Mackenzie, 1996), Gustavo Cedroni, Martin Corullon e Cesar Shundi; e os colaboradores: Alex Lima (Mackenzie, 2008), Andrei Barbosa Bruno Salvador, Bruno Jin Young Kim,

Dulci Cipriano (Mackenzie, 2013), Felipe Fuchs, Filipe Barrocas, Maria Francisca Lopes, Marcelo Macedo (Mackenzie, 2011), Marina Ioshii, Luis Tavares, Paula Hori (Mackenzie, 2012), Rafael Goffinet, Rafael Carvalho e Rafael de Souza.

27. A concepção do projeto contou com a colaboração dos Arquitetos Katherina Ortner e Sebastian Murr.

28. Coautores: Alessandra Mattar (Mackenzie, 2011), Alexandra Kayat (Mackenzie, 2010), Eduardo Mikowski (Mackenzie, 2013), Gabriel Ranieri, Nara Telles (Mackenzie,2012), Pedro Ribeiro, Raul Cano.

\begin{abstract}
De um total de 106 inscritos, a comissão julgadora selecionou seis trabalhos, que deveriam contemplar uma visão da área em um horizonte de 20 anos, abordando os aspectos de desenvolvimento e mobilidade urbana que têm como base os "10 Princípios da Mobilidade Urbana Sustentável" [...] Considerado ousado nas propostas, inclusive na extensão para o sistema viário e de transporte, o projeto vencedor tem forte preocupação com acessibilidade de pedestres e ciclovias, reconhece a importância histórica do local, além de propor construções de uso misto em espaços ociosos.
\end{abstract}

A partir de 2012, certames internacionais fechados também chamariam a atenção. No Concurso para o Centro de Conferências em Libreville, organizado pelo governo do Gabão (CENTRO DE CONFERÊNCIAS, 2012), a equipe ${ }^{26}$ do Arquiteto convidado Pedro Paulo de Melo Saraiva (Mackenzie,1955) conquistou o segundo lugar, em decisão emitida em meio a uma disputa acirrada. A proposta ficou à frente de outras apresentadas por grandes Arquitetos internacionais, como Norman Foster, Zaha Hadid, Renzo Piano, Jean Nouvel, Frank Gehry, Rem Koolhaas, Jacques Herzog e Pierre de Meuron. O desenho destacava-se por sua precisão e simplicidade, o que, segundo os Arquitetos, era cilíndrico e qualificado como etéreo. O novo Palácio de Conferências teria o atributo de símbolo da reunião dos povos africanos em torno dos princípios de liberdade, tolerância e desenvolvimento democrático sustentável (CENTRO DE CONFERÊNCIAS, 2012). No mesmo ano, Isay Weinfeld (Mackenzie, 1975) foi convidado a participar do Concurso para uma Torre Residencial em Monte Carlo - La Petite Afrique, organizado pela empresa PROTEA S.A.M, que têm entre os sócios os Príncipes de Mônaco. A equipe ${ }^{27}$ do Arquiteto obteve o primeiro prêmio após competir com projetos de Jean Nouvel, Kengo Kuma, David Adjaye e Shigeru Ban. A proposta destacou-se pela discrição no contexto do que foi denominado cidade-estado, e pela vegetação exuberante que se articulava com a Arquitetura (WEINFELD, 2017). Em outra ocasião, quatro anos depois, o Arquiteto também foi selecionado no Concurso Internacional para a Realocação do Restaurante The Four Seasons (concurso fechado), este último localizado no edifício de Philip Johnson e Mies van der Rohe, o icônico Seagram Building em Nova lorque - o local é conhecido por ser um dos últimos ambientes completamente modernos de Manhattan (HOWARTH, 2016).

Ainda em um contexto internacional, o Concurso Público Nacional de Arquitetura de Expografia para o Pavilhão do Brasil na Expo Milão de 2015, organizado pelo IAB-DF e Apex Brasil em 2014, premiou com a primeira colocação a equipe ${ }^{28}$ de Arthur de Mattos Casas, afirmando que: "Esta proposta se destacou especialmente por apresentar originalidade e coerência entre os projetos de Arquitetura e expografia, concebidos como um todo coeso e indissociável, segundo um conceito denso e original" (BARATTO, 2015, p. 2). Também em 2014, a equipe de Daniel Corsi, Dani Hirano, André Sauaia e Laura Pardo, venceu em primeiro lugar o Concurso para a Sede Administrativa da Câmara Municipal de Porto Alegre, organizado pelo IAB-RS (SEDE ADMINISTRATIVA, 2014). A consagração da equipe já havia se dado em 2009, na ocasião do primeiro lugar obtido no Concurso Internacional para Projeto Arquitetônico do Museu Exploratório de Ciências da Unicamp, organizado pelo IAB-SP 
(MUSEU EXPLORATÓRIO, 2009); os autores Corsi, Hirano e Nishimura tiveram a colaboração de Sauaia e Pardo. Ambas as edificações, em estrutura metálica, apresentam rigor técnico e ordenação espacial rigorosa, características dos Arquitetos.

Um dos destaques da década foi o emblemático Concurso de Projetos do Prédio Anexo do BNDES, Rio de Janeiro (PREMIADOS, 2014), organizado pela instituição financeira no final de 2014. Impasses jurídico-administrativos cercaram a participação dos Arquitetos no certame público. Tais questões não impediram que fosse premiada em segundo lugar a equipe ${ }^{29}$ dos recém-formados Pedro Ivo, Anna Juni, Henk te Winkel e Gustavo Delonero, os três últimos egressos em 2013, 2012 e 2011 respectivamente. Segundo a ata do júri: "A proposta manteve a racionalidade e boa distribuição dos espaços, além de apresentar notável evolução entre as duas etapas do concurso, alcançando solução otimizada para os pavimentos tipo" (PREMIADOS, 2014).

Por fim, o Concurso Público de Arquitetura da Nova Sede do CAU-BR + IAB-DF organizado pelas entidades selecionou em primeiro lugar, entre 218 propostas, aquela da equipe de Tais Cristina da Silva (Mackenzie, 2004), Paulo Roberto dos Santos, Cassio Oba (Mackenzie, 2007), Gabriel Cesar e Santos (Mackenzie, 2008) e Eugenio Conte (Mackenzie, 2009). O projeto das duas principais instituições que simbolizam os Arquitetos no Distrito Federal representou grande desafio nas condições do Edital, tanto no que diz respeito ao arranjo das hierarquias espaciais quanto à inserção no lote. Contudo, o júri destacou a proposta pela qualidade da implantação que concentrou o edifício em uma porção do terreno e liberou a outra para uma praça, além da clareza da espacialidade e atendimento do programa, "além da imagem forte e austera, sem excessos plásticos desnecessários" (ARCHDAILY BRASIL, 2016).

Os concursos de projeto anteriormente listados são, certamente, uma pequena amostra da recorrente participação de Arquitetos mackenzistas em importantes certames. Tradição, compromisso e responsabilidade acompanham as transformações da Arquitetura, e os Arquitetos formados pela FAU-Mackenzie são agentes da mudança, sem, no entanto, tomá-la de pronto.

\section{Mackenzistas recém-formados e o Concurso Opera Prima (1989-2016)}

A história da FAU-Mackenzie está intensamente relacionada à formação de Arquitetos e Urbanistas e sua prática do projeto. Uma das características da formação nessa Faculdade é a abordagem realista que propõe desafios técnicos, permitindo ao estudante ou jovem Arquiteto se inserir no mercado de trabalho de maneira não apenas participativa, mas inovadora, e com a qualidade reconhecida ao longo dos anos. Aqueles que passaram pela FAU-Mackenzie certamente compreendem que Arquitetura e Urbanismo devem ser pensados não como disciplinas isoladas, fruto de um saber particular, mas sobretudo com a abrangência necessária de formação que contribua para um viver mais humano.
29. Também colaboraram: André Nunes, Florencia Merguerian, João Sodré, Julia Reis (Mackenzie, 2013), Marina Canhadas (Mackenzie, 2008), Bruno Carnevalli (Mackenzie, 2011), Guilherme Tanaka, Júlia Masagão, Raul Pereira, Leandro Fontana, Rulian Nociti, Paula Martins, Cláudia Kawakami e Rui Furtado. 


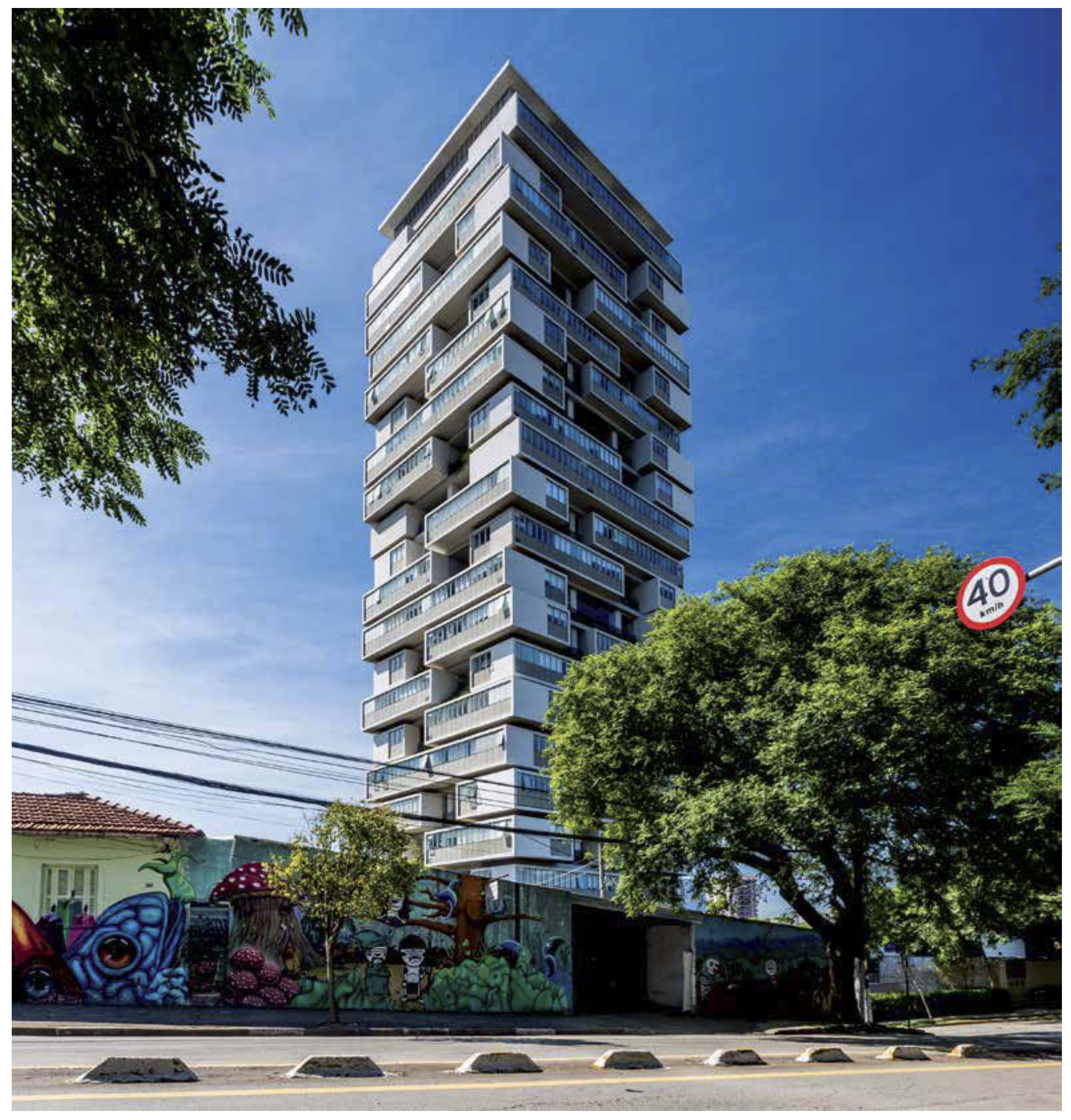


Uma das marcas dessa formação torna-se tangível no Trabalho Final de Graduação, ${ }^{30}$ que tem caráter duplo na vida do Arquiteto e Urbanista: configura a etapa final do Curso e a porta de entrada do exercício profissional. Para muitos, esse é um momento de amadurecimento profundo, de consolidação de aprendizados e enfrentamento de questões cujas respostas estão sempre em processo, nunca definitivas. Os resultados dessa experiência revelam-se marcantes na carreira dos estudantes, que o Opera Prima, ${ }^{31}$ desde 1988 , vem registrando por meio da premiação e destaque de trabalhos de egressos de todo o Brasil.

Durante as várias edições do Prêmio, a presença dos formandos da FAU-Mackenzie sempre foi significativa. O reconhecimento de trabalhos de graduandos do Mackenzie já ocorria antes da existência dessa premiação. A Projeto Design, ${ }^{32}$ uma das mais importantes publicações do segmento no país, desde seu início em 1977 já publicava trabalhos finais de graduação. Nas décadas de 1980 e 1990, o Trabalho Final de Graduação ganhou notoriedade na revista e em outros meios de comunicação, com a publicação de matérias escritas por Arquitetos e Urbanistas a respeito. Nesse período, um destaque foi o trabalho de graduação do Arquiteto mackenzista Mario Biselli, publicado em dezembro de 1986 na então Revista Projeto no 94 (SERAPIÃO, 2008). O então estudante buscou uma linguagem arquitetônica que evidenciasse características simbólicas da própria cidade (OS SIMBOLISMOS, 1986, p. 96):

[...] o simbolismo pode ser de ordem coletiva, assim como o edifício Banespa, que a silhueta mais marcante na memória do cidadão paulistano, ou de ordem individual, por exemplo nos brises horizontais do edifício da antiga TV Tupi e do Conjunto Nacional.

À medida que os trabalhos de graduação ganhavam notoriedade pela qualidade das propostas dos jovens Arquitetos, o Concurso Opera Prima foi idealizado pela então Revista Projeto (hoje Projeto Design) em parceria com a Associação Brasileira de Ensino de Arquitetura (Abea). ${ }^{33}$ Em 15 de agosto de 1988, na Faculdade de Arquitetura e Urbanismo da Universidade de São Paulo (FAU-USP), lançou-se oficialmente o concurso, cuja Comissão Organizadora foi formada pelo editor da Projeto Design, Vicente Wissenbach, e o presidente da Abea, Carlos Maximiliano Fayet, com o patrocínio da FADEMAC, empresa fabricante de pisos vinílicos.

A seleção dos trabalhos realizou-se em três etapas: na primeira, houve uma chamada interna, e cada escola deveria escolher de um a dez trabalhos; na segunda, de nível regional, um corpo de jurados composto por três profissionais locais escolheriam os cinco melhores trabalhos de cada região (sendo no total cinco regiões); na terceira e última, denominada nacional, os 25 finalistas foram novamente avaliados por um júri nacional composto pelos Arquitetos Cláudio Araújo, Hugo Segawa, Luiz Paulo Conde, Luciano Guimarães e Severiano Porto. Esse grupo de profissionais reuniu-se na Universidade Presbiteriana Mackenzie (UPM) e selecionou os cinco melhores trabalhos, elegendo um vencedor nacional entre 1.560 formandos (SERAPIÃO, 2008).
Na página anterior:

Edifício 360, São Paulo, 2013. Projeto do Arquiteto Isay Weinfeld (Mackenzie, 1975).

30. O TFG é a atividade prevista pelo Ministério da Educação e Cultura (MEC) como Trabalho de Conclusão de Curso. Segundo o parecer da Comissão de Especialistas de Ensino de Arquitetura e Urbanismo: "A área de ensino de Arquitetura e Urbanismo se antecipou às determinações legais (Le no 9131/95), que estabeleceram para o ensino superior, a partir de 1996, um exame dos alunos ao final de Curso, e desde 1994 incluiu, entre as exigências curriculares obrigatórias para todos os cursos e alunos formandos, a realização do Trabalho Final de Graduação". (UNIVERSIDADE PRESBITERIANA MACKENZIE, 2001).

31. O Prêmio Opera Prima tornou-se referência nacional como concurso de trabalhos finais de graduação em Arquitetura e Urbanismo. Desde sua criação, contou com júris formados por profissionais mackenzistas de grande competência, como Fabio Penteado, Paulo Mendes da Rocha, Alfredo Paesani, Alberto Botti e Marcio Kogan.

32. A Projeto Design é uma revista brasileira, da editora Arco Editorial que existe há aproximadamente 40 anos, com edições mensais dirigidas a profissionais da área de Arquitetura e Urbanismo. Sua primeira edição, ainda com a denominação de Revista Projeto, foi a de número 11, porque essa era uma publicação originária do Jornal Arquiteto de 1972. O jornal era ligado ao IAB-SP e foi criado por Vicente Wissenbach.

33. A Abea contribui para a elaboração da política de avaliação e regulação dos cursos junto ao MEC. 
A publicação do resultado do primeiro Opera Prima foi realizada na então Revista Projeto no. 114 (1989), no espaço reservado à Abea. Para a escolha do primeiro colocado, foram selecionados os melhores trabalhos finais de graduação produzidos nas escolas de Arquitetura e Urbanismo de todo o Brasil (SERAPIÃO, 2008). Além disso, a Abea estimulava a realização de um panorama anual e documental das escolas, podendo assim conhecer o perfil do ensino de cada escola e promover o debate entre instituições e seus alunos. A edição seguinte da Projeto Design apresentou todos os detalhes sobre o Prêmio que contou com a participação de 48 escolas, incluindo a FAU-Mackenzie, que nessa primeira edição recebeu um Destaque e quatro Menções Honrosas (Rubens Aparecido dos Reis, Adriana Gomes Coelho, Ana Cláudia S. de Oliveira, Mariza Scavazza Vanzella e Sônia Maria de Andrade Gottardi, respectivamente).

O Prêmio Opera Prima desde seu lançamento, em 1988, passou por vários aprimoramentos dos critérios de escolha dos melhores trabalhos finais de conclusão dos cursos de Arquitetura denominados de diversas formas ao longos destes anos: TG (Trabalho de Graduação), TGI (Trabalho de Graduação Interdisciplinar), ou TFG (Trabalho Final de Graduação - nomenclatura atual). Nas 11 primeiras edições (1989-2000), o prêmio esteve fortemente vinculado à Abea. No segundo momento, dez edições (2001-2011) permaneceram sob a entidade profissional, o Instituto de Arquitetos do Brasil/Direção Nacional (IAB/DN). No ano seguinte, a Revista Projeto Design passou a coordenar a premiação, o que perdura até hoje (ROCHA, 2016; SERAPĨ̃O, 2008).

Nas diferentes fases do concurso, bem como nas décadas em que cada entidade organizadora atuou, houve mudanças nos critérios de julgamento, formas de elaboração de atas, de participação, bem como na própria divulgação dos resultados. Essas alterações certamente indicam transformações que se deram ao longo dos anos respeitando orientações do MEC, bem como o aumento do número de cursos de Arquitetura no país e, consequentemente, do número de participantes. Tais critérios evoluíram até os dias de hoje, aperfeiçoando a premiação que contou com apenas uma pausa, ocorrida em 2012 (ROCHA, 2016).

Além de transformações institucionais da formação profissional do Arquiteto e Urbanista, as mudanças de rumo que a sociedade atravessa foram certamente traduzidas, em alguma medida, nos trabalhos que resultam os TFGs. Por meio do desenho e do discurso, como expressões de desejo e postura, evidencia-se grande responsabilidade social que se reflete nas escolhas temáticas dos estudantes de Arquitetura e Urbanismo ao realizar esse tipo de trabalho. Desde a temática a ser abordada até a metodologia de elaboração e o desenvolvimento do projeto, cada trabalho expressa preocupações que determinada geração de Arquitetos(as) e Urbanistas valoriza, pouco antes de ingressar no campo profissional.

Na maioria das edições do Concurso, os estudantes da FAU-Mackenzie foram reconhecidos com premiação, menção honrosa ou destaque, conforme aponta o Quadro 1. Diante de número significativo de cursos de Arquitetura e Urbanismo no país, ser frequentemente laureado no Opera Prima é um importante indício da qualidade da formação dos estudantes dessa Escola e, consequentemente, de seus egressos e recém-formados. 
Quadro 1 - Levantamento dos Mackenzistas laureados no Ópera Prima - da primeira edição até hoje

\begin{tabular}{|c|c|c|c|}
\hline ANO & CLASSIFICAÇÃO & ESTUDANTE(ES) & ORIENTADOR(ES) \\
\hline \multirow{4}{*}{1989} & \multirow{4}{*}{ Menção honrosa } & Adriana Gomes Coelho, Ana Cláudia & \multirow{4}{*}{ Sami Bussab } \\
\hline & & S. de Oliveira, Mariza Scavazza & \\
\hline & & Vanzella, Sônia Maria de Andrade & \\
\hline & & Gottardi & \\
\hline 1989 & Destaque & Rubens Aparecido dos Reis & Antônio Carlos Sant'Anna Jr. \\
\hline \multirow[b]{2}{*}{1990} & \multirow[b]{2}{*}{ Prêmio Opera Prima } & Álisson Macedo e José Gustavo & \multirow[b]{2}{*}{ Tito Lívio Frascino } \\
\hline & & Crespo Barreiros & \\
\hline \multirow{2}{*}{1990} & \multirow{2}{*}{ Menção honrosa } & Antônio Medeiros Rodrigues e & \multirow{2}{*}{ Antônio Carlos Sant'Anna Jr. } \\
\hline & & Eduardo Cordeiro Araújo & \\
\hline 1991 & Menção honrosa & Maria de Fátima Idalina Torres Pereira & Tito Lívio Frascino \\
\hline 1992 & Menção honrosa & Glauco Corrêa Porto Tonon & Antônio Carlos Sant'Anna Jr. \\
\hline \multirow{2}{*}{1993} & \multirow{2}{*}{ Menção honrosa } & Alessandra Paschoal e Ricardo & Eduardo N. M. Ferreira e Tito Lívio \\
\hline & & Gardinal & Frascino \\
\hline \multirow[b]{2}{*}{1994} & \multirow[b]{2}{*}{ Menção honrosa } & Lee Yueh Ju e Paulo Goyano de Faria & \multirow[b]{2}{*}{ Gilberto Belleza e Carlos H. Heck } \\
\hline & & Júnior & \\
\hline 1995 & Menção honrosa & Arthur Delgado & Tito Lívio Frascino \\
\hline 1997 & Prêmio Opera Prima & Andréa dos Santos Castanheira & Tito Lívio Frascino \\
\hline 1997 & Menção honrosa & Antonio Tetsuo Kanda & Sami Bussab \\
\hline 1998 & Prêmio Opera Prima & Maurício Lamosa Nunes & Ruth Verde Zein \\
\hline 1998 & Menção honrosa & Felipe Rodrigues de Almeida & Joan Villà Martinez \\
\hline \multirow{2}{*}{2000} & \multirow{2}{*}{ Prêmio Opera Prima } & Flávio Galvão de França e Juan Pablo & \multirow{2}{*}{ Tito Lívio Frascino e Ruth Verde Zein } \\
\hline & & Rosenberg & \\
\hline 2000 & Menção honrosa & Fernanda S. Ferreira e Stephan Steyer & Sami Bussab e Ruth Verde Zein \\
\hline 2001 & Menção honrosa & Juliana Pellegrini Lemos & Anne Marie Summer \\
\hline 2002 & Prêmio Opera Prima & Danielle de Cassia Spadotto & José Luiz Tabith Jr. \\
\hline \multirow{3}{*}{2003} & \multirow{3}{*}{ Menção honrosa } & Pedro de Mello Ribeiro, Priscila & \multirow{3}{*}{$\begin{array}{l}\text { Ruth Verde Zein, Joan Villà e Pedro } \\
\text { Paulo de M. Saraiva }\end{array}$} \\
\hline & & Tavares Teves e Renato Afonso Dala & \\
\hline & & Marta & \\
\hline 2004 & Prêmio Opera Prima & Fernanda Kleemann Spinicci & Pedro Nosralla Junior \\
\hline \multirow{2}{*}{2004} & \multirow{2}{*}{ Menção honrosa } & Carolina Pons Esparó e Cristiane & \multirow{2}{*}{ Sami Bussab e José Luiz Tabith Jr. } \\
\hline & & Fraga Vasquez & \\
\hline \multirow{2}{*}{2005} & \multirow{2}{*}{ Prêmio Opera Prima } & Gustavo Oliveira Policarpo da Luz e & Gilberto Belleza e Pedro Paulo de M. \\
\hline & & Taís Lie Okano & Saraiva \\
\hline 2006 & Menção honrosa & Camila Fernandes Malito & Sami Bussab \\
\hline \multirow{2}{*}{2007} & \multirow{2}{*}{ Menção honrosa } & Fabio Manoel Pereira de Bem e Felipe & Angélica Tanus Benatti Alvim, Luciano \\
\hline & & Martin de Góes & Margotto e Pedro Nosralla Junior \\
\hline 2008 & Prêmio Opera Prima & Maria Fernanda Ribeiro Ornelas & Lucas Fehr \\
\hline & & Cassia Lopes Moral, Cassio Oba & Tito Lívio Frascino e Joan Villà \\
\hline & & Osanai e Renata Gonçalves Mendes & Martinez \\
\hline
\end{tabular}


Jardim do Conjunto Nacional, São

Paulo, 1997. Projeto da Arquiteta

Maria Cecília Barbieri Gorski

(Mackenzie, 1976) e do Arquiteto

Michel Gorski (Mackenzie, 1976).

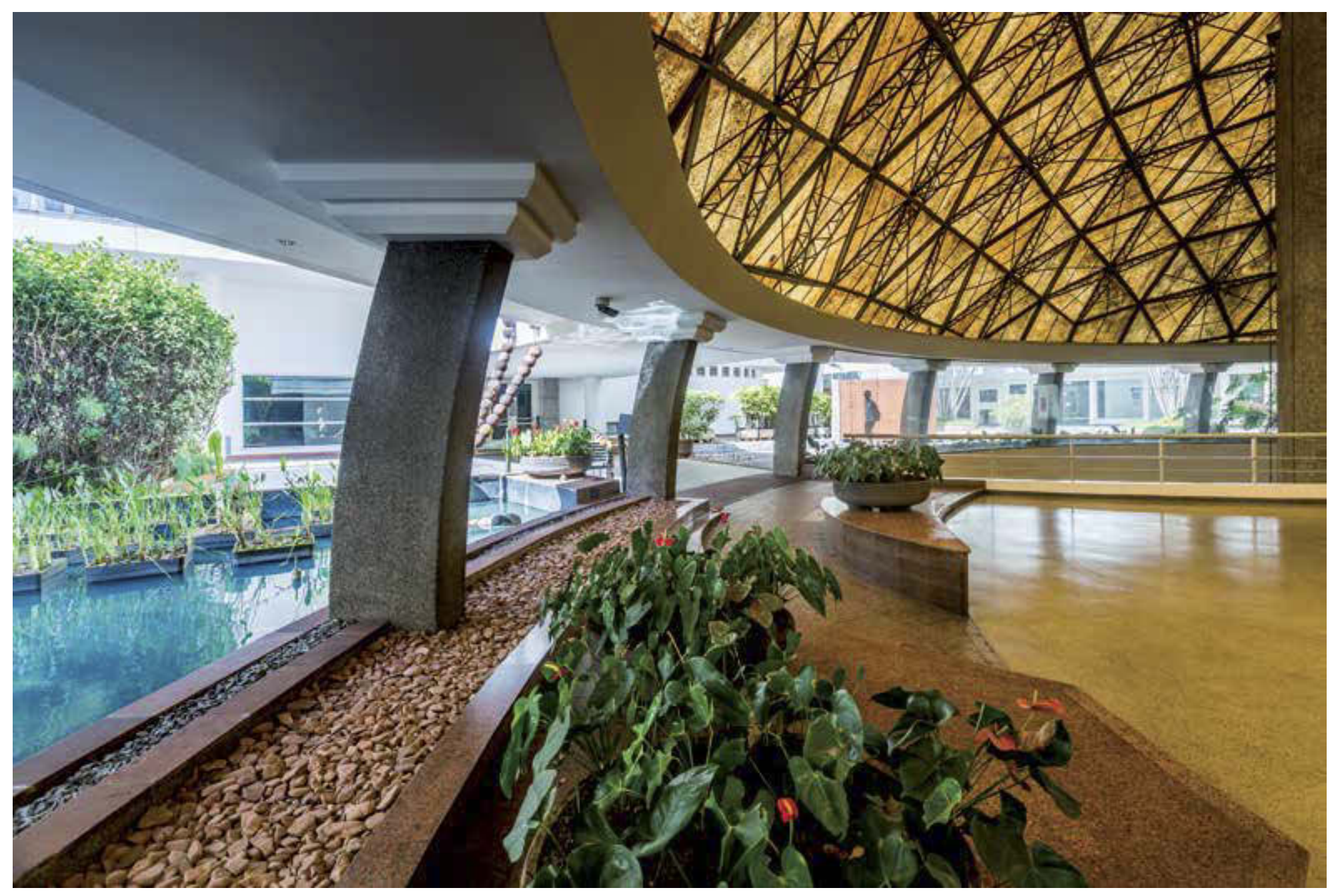


Quadro 1 - Levantamento dos Mackenzistas laureados no Ópera Prima - da primeira edição até hoje (continuação)

\begin{tabular}{llll}
\hline ANO & CLASSIFICAÇÃo & ESTUDANTE(ES) & ORIENTADOR(ES) \\
\hline 2009 & Menção honrosa & Evangelina Lopes Nunes Galvão & $\begin{array}{l}\text { Antonio Cláudio Fonseca e Marcelo } \\
\text { Consiglio Barbosa }\end{array}$ \\
\hline 2010 & Menção honrosa & Cristiane Sbruzzi de Paula Cardoso & Pedro Nosralla Junior \\
\hline 2011 & Menção honrosa & $\begin{array}{l}\text { Mario Aldegheri do Val,Heitor Savala } \\
\text { dos Santos e Juliana Papis Baldocchi }\end{array}$ & $\begin{array}{l}\text { Angelo Cecco Junior, Gilberto Belleza e } \\
\text { José Luiz Tabith Jr. }\end{array}$ \\
\hline 2013 & Vencedor nacional & Henrique Martin Te Winkel & Antônio Carlos Sant'Anna Jr. e Júlio Luiz \\
\hline 2014 & Vencedor nacional & Raíssa Bahia Lopes & Vieira \\
\hline 2015 & Finalista regional & Marcelo Ribeiro de Souza Ribas & Lucas Fehr e Abilio Guerra \\
\hline 2016 & Vencedor nacional & Alice Barrachini Torres & Pedro Nosralla Junior \\
\hline
\end{tabular}

Fonte: Dados fornecidos por Vanilda Queiroz Sganzerla que compõe a Coordenação do Prêmio Opera Prima. ${ }^{34}$

A participação dos recém-formados do Mackenzie e sua atuação relevante no Opera Prima por meio dos TFG(s) indicam como a Faculdade tem se mantido atenta a essas transformações e tem valorizado por meio de concursos a atuação de seus discentes, louvando a maneira responsável preconizada diante dos desafios de projetar os espaços da sociedade contemporânea, motivo de celebração, sem dúvida.

No cenário nacional predominantemente urbano, o ensino de Arquitetura e Urbanismo é fundamental para a formação profissionais de espírito desbravador e interessados em elaborar e propor soluções possíveis às novas demandas da sociedade. O espírito do tempo deve acompanhar a Arquitetura e o Urbanismo, fazendo desta seu testemunho e materialização.

As palavras da então recém-formada Arquiteta Alice Barachini Torres, vencedora nacional em 2016, deixa clara a visão profissional vinculada à responsabilidade social e ao espírito coletivo:

Foi com muita felicidade, após a defesa deste trabalho, que este recebeu a indicação para - $27^{\circ}$ Concurso Opera Prima, e posteriormente fui eleita um dos vencedores nacionais da edição. Sabe-se que a participação em concursos são de extrema relevância para a profissão do arquiteto e urbanista e para a sociedade. Através deles, dá-se o desenvolvimento de propostas de caráter mais inventivo, criativo, a possibilidade do aprimoramento e exercício do arquiteto, para situações de desenho urbano, para edifícios de caráter público, cultural, dentre outros. Com a apresentação de propostas variadas para uma mesma situação, por exemplo, por diferentes profissionais da área, são enriquecedoras as discussões sobre as nossas cidades e espaços, tornando-os melhores e mais democráticos.
34. Conforme dados coletados junto à coordenação do Prêmio Opera Prima, desde seu lançamento em 1988 (cuja finalização da edição foi em 1989) até hoje, houve apenas uma interrupção, no ano de 2012. E, por esse motivo a $24^{a}$ edição realizada em 2013 foi aberta a participação dos formandos de 2011 e 2012 de forma a não interromper o ciclo dos formandos. 
35. Entrevista realizada por Vinicius da Costa em março de 2017.
O Opera Prima, para o arquiteto e urbanista recém formado, é não só uma oportunidade de inserção no mercado, mas do reconhecimento da importância do seu trabalho, como uma contribuição. É a oportunidade para apontar questões, problemas, com ampla liberdade, e de oferecer soluções criativas que serão debatidas e estimadas..$^{35}$

\section{Considerações finais}

"Já existia arquitetura muito antes de existirem os arquitetos. No entanto, pode se dizer que a profissão, tal como a conhecemos hoje, deve a sua existência aos concursos de arquitetura" (ALEXANDRE, 2016, p. 7).

O corpo teórico e imagético de proposições enunciadas em cada concurso, ou da soma deles presente objetivamente ou não na paisagem, se torna um arcabouço de reflexões sobre a totalidade da profissão de Arquiteto e Urbanista.

Na FAU-Mackenzie, oportunidade e vontade se encontram nos concursos de Arquitetura. Por um lado, significa a vontade de quem demanda e premia pela possibilidade de tornar públicos as exigências e os sonhos de cidade, do edifício, e dos espaços que indiquem uma existência futura; por outro, a oportunidade de os Arquitetos responderem propondo caminhos para o corpo individual e social, tangibilizando o palco da vida em sociedade. Sem dúvida, um grande legado dos concursos de Arquitetura reside na confluência de profissionais: jovens Arquitetos têm a oportunidade de iniciar carreira, e Arquitetos consagrados podem se reinventar no percurso; ambos, nessa trajetória, se encontram nos caminhos da transformação.

\section{Referências}

$1^{\circ}$ INTERNATIONAL COMPETITION GLOBAL House 2005 for Young Architects. Portal Vitruvius, 3 jul. 2006. Disponível em: <http://www.vitruvius.com.br/revistas/read/projetos/06.067/2687 >. Acesso em: 12 jun. 2017.

ALEXANDRE, R. Para que não se deixe soterrar um legado na espessura do tempo. In: BAPTISTA, L. S. (Coord.). Arquitetura em Concurso: percurso crítico pela modernidade portuguesa. Porto: Dafne Editora, 2016.

A BAIANIDADE DE CASAS. Projeto Design, São Paulo, n. 386, abr. 2012. 
ARCHDAILY BRASIL. Divulgado o resultado do concurso nacional para a nova sede do CAU/BR + IAB/DF. ArchDaily, 14 nov. 2016. Disponível em: <http://www.archdaily.com.br/ br/799421/divulgado-o-resultado-do-concurso-nacional-para-a-nova-sede-do-cau-br-plus -iab-df>. Acesso em: 16. jun. 2017.

BAETA, A. P. As vantagens dos concursos para a contratação de projetos. Instituto de Arquitetos do Brasil, 9 dez. 2014. Disponível em: <http://www.iab.org.br/artigos/vantagensdos-concursos-para-contratacao-de-projetos>. Acesso em 16 abr. 2017.

BARATTO, R. Resultados do concurso para o Pavilhão do Brasil na Expo Milão 2015. ArchDaily, 27 jan. 2014. Disponível em: <http://www.archdaily.com.br/br/01-171436/resultados-do-concurso-para-o-pavilhao-do-brasil-na-expo-milao-2015>. Acesso em: 25 fev. 2017.

BRASILEIROS SE DESTACAM em concurso internacional. Projeto Design, São Paulo, n. 311, p. 18, jan. 2006.

CENTRO DE CONFERÊNCIAS EM LIBREVILLE. Portal Vitruvius, ano 12, n. 142.01, dez. 2012. Disponível em: <http://www.vitruvius.com.br/revistas/read/projetos/12.142/4589>. Acesso em: 12 jun. 2017.

CONCURSO "A CIDADE SOMOS NÓS - Propostas para a São Paulo de 2030" contempla 6 trabalhos. Vitruvius, 23 set. 2011. Disponível em: <http://www.vitruvius.com.br/jornal/news/ read/1025>. Acesso em: 13 jun. 2017.

CONCURSO BAIRRO NOVO. Portal Vitruvius, ano 4, n. 044.02, ago. 2004. Disponível em: <http://www.vitruvius.com.br/revistas/read/projetos/04.044/2398?page=8 > . Acesso em: 12 jun. 2017.

CONCURSO INTERNACIONAL PARA PROJETO Arquitetônico do Museu Exploratório de Ciências da Unicamp. Portal Vitruvius, ano 9, n. 106.02, out. 2009. Disponível em: <http:// www.vitruvius.com.br/revistas/read/projetos/09.106/2978>. Acesso em: 13 out. 2009.

CONCURSO NACIONAL CENTRO JUDICIÁRIO DE CURITIBA. Portal Vitruvius, São Paulo, ano 6, n. 065.04, 18 abr. 2006. Disponível em: <http://www.vitruvius.com.br/revistas/read/projetos/06.065/2648>. Acesso em: 13 maio 2006.

CONCURSO PÚBLICO NACIONAL DE ARQUITETURA PARA O TEATRO MUNICIPAL DE LONDRINA - PR - Londrina. Portal Vitruvius, n. 080.01, ano 7, jul. 2007. Disponível em: <http://www.vitruvius.com.br/revistas/read/projetos/07.080/2824>. Acesso: 12 jun 2017. 
Edifício Vertical Itaim, São Paulo, 2014. Projeto dos Arquitetos Marcio Kogan (Mackenzie, 1976) e Carolina Castroviejo (Mackenzie, 2003).

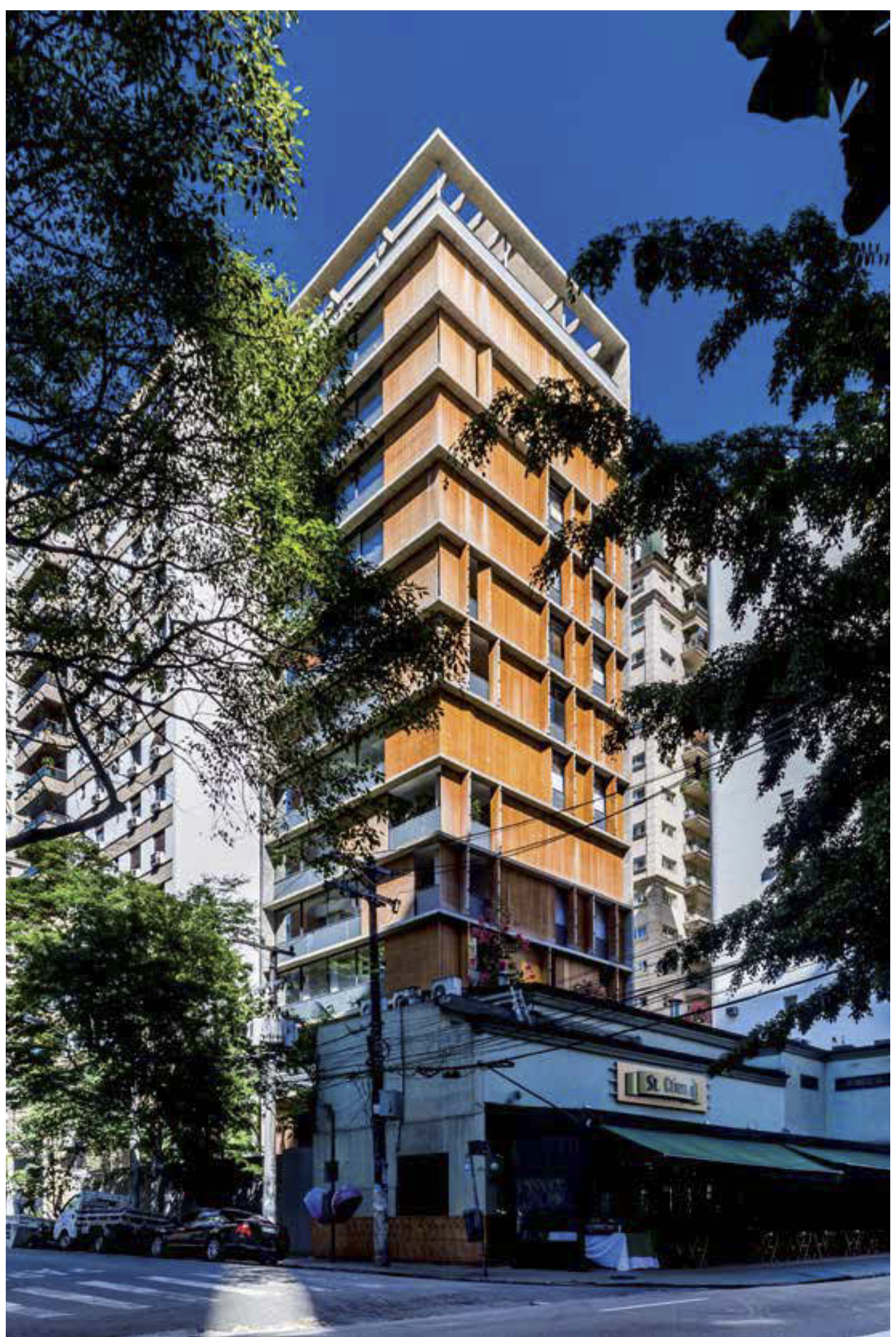


CONCURSO PÚBLICO NACIONAL DE ARQUITETURA - Sede da Procuradoria Regional da República da 4 a Região - PRR4 - Portal Vitruvius, n. 043.03, ano 4, jul. 2004. Disponível em:<http://www.vitruvius.com.br/revistas/read/projetos/04.043/2384?page=2> . Acesso em: 12 jun. 2017.

CONCURSO PÚBLICO NACIONAL DE IDEIAS - Requalificação de Largos no Pelourinho. ConcursosDeProjetos.org, 9 nov. 2011. Disponível em: <https://concursosdeprojeto. org/2011/11/09/concurso-equalificacao-de-largos-no-pelourinho/>. Acesso em: 12 jun. 2017.

CONCURSO PÚBLICO NACIONAL RECONVERSÃO URBANA DO LARGO DA BATATA. Portal Vitruvius, São Paulo, ano 2, n. 17, mar. 2002. Disponível em: <http://www.vitruvius.com.br/ revistas/read/projetos/02.017/2143>. Acesso em: 13 mar. 2002.

FERRONI, E. Aproximações sobre a obra de Salvador Candia. 2010. Dissertação (Mestrado em Arquitetura)-Universidade de São Paulo, São Paulo, 2010.

FIALHO, V. S. Concursos de arquitetura: processos e evolução. Revista Se, n. 3, 2001.

FINALISTAS DO AEROPORTO de Florianópolis. Projeto Design, São Paulo, n. 292, p. 17, jun. 2004.

GAUSA, M. Diccionario Metápolis arquitectura avanzada: ciudad y tecnologia en la sociedad de la información. Barcelona: ACTAR, 2000.

GIMENEZ, L. E. Pedro Paulo de Melo Saraiva, arquiteto. São Paulo: Romano Guerra, 2016.

GRUNOW, E. O eloquente Opera Prima. Projeto Design, n. 431, 2016. Disponível em: <https:// arcoweb.com.br/projetodesign/especiais/o-eloquente-opera-prima>. Acesso em: 9 abr. 2017.

HOUAISS, A. Dicionário eletrônico Houaiss da língua portuguesa. Versão 2.0. São Paulo: Objetiva, 2008. Disponível em: <http://clicandodegraca.blogspot.com.br/2008/02/dicionrio -eletrnico-houaiss-da-Ingua.html> . Acesso em: 12 jun. 2017.

HOWARTH, D. Isay Weinfeld to design relocated The Four Seasons restaurant in New York. Dezeen, 19 jul. 2016. Disponível em: <https://www.dezeen.com/2016/07/19/isay-weinfelddesign-relocated-the-four-seasons-restaurant-new-york-280-park-avenue/>. Acesso em: 12 jun. 2017.

MAGALHÃES, S. Cultura fatiada. O Globo, Rio de Janeiro, 10 set. 2016.

MELENDEZ, A. Estúdio América: Museu em Santiago. Arca flutuante carrega memória dos anos de chumbo no Chile. ArcoWeb, 2010. Disponível em: <https://arcoweb.com.br/ projetodesign/arquitetura/estudio-america-museu-santiago-09-06-2010>. Acesso em: 13 maio 2017. 
MUSEU EXPLORATÓRIO DE CIÊNCIAS DA UNICAMP - Projetos Premiados e Menções. ConcursosDeProjetos.org, 17 ago. 2009. Disponível em: <https://concursosdeprojeto. org/2009/08/17/museu-unicamp-projetospremiados/> . 2014. Acesso em: 12 jun. 2017.

NOVA FACHADA PARA O EDIFÍCIO DAS ARCADAS. Revista Au, ed. 143, fev. 2006. Disponível em: <http://www.au.pini.com.br/arquitetura-urbanismo/143/artigo22095-1.aspx>. Acesso em: 13 jan. 2017.

OS SIMBOLISMOS DA CIDADE num projeto de hotel. Projeto Design, São Paulo, n. 94, dez. 1986.

PREMIADOS - Concurso Paço Municipal de Várzea Paulista - SP. ConcursosDeProjetos.org, 21 ago. 2012. Disponível em:<https://concursosdeprojeto.org/2012/08/19/premiados-concursopaco-municipal-de-varzea-paulista/> . Acesso em: 12 jun. 2017.

PROJETO. Os simbolismos da cidade num projeto de hotel. Trabalho de Graduação, Mário Biselli, Projeto, n. 94, p. 96, dez. 1986.

SEGUNDA COBERTURA AGRUPA SAGUÃO E QUATRO AUDITÓRIOS. Projeto Design, n. 312, p. 86-89, fev. 2006.

RAMOS, R. C. L. Densidades urbanas e o concurso Bairro Novo. 2010. Dissertação (Mestrado em Arquitetura e Urbanismo)-Universidade Presbiteriana Mackenzie, São Paulo, 2010.

REVISTA SE... Editorial. São Paulo: Faculdade de Arquitetura e Urbanismo: Universidade Presbiteriana Mackenzie, n. 3, dez. 2001.

ROCHA, B. A. da. O concurso para formados de Arquitetura e Urbanismo Opera Prima: 19892011. 2016. Dissertação (Mestrado em Arquitetura e Urbanismo)-Universidade Estadual de Campinas, Campinas, 2016.

SANTAELLA, L.; NÖTH, W. Imagem: cognição, semiótica, mídia. 2. ed. São Paulo: Iluminuras, 2010.

SEDE ADMINISTRATIVA DA CÂMARA MUNICIPAL de Porto Alegre. $1^{\circ}$ lugar - Corsi\&Hirano. Portal Vitruvius, São Paulo, ano 14, n. 166.01, 2014. Disponível em: <http://www.vitruvius.com. br/revistas/read/projetos/14.166/5347> . Acesso em: 14 out. 2014.

SEDE DA PETROBRAS EM VITÓRIA ES VITÓRIA. Portal Vitruvius, n. 056.01, ano 5, ago. 2005. Disponível em: <http://www.vitruvius.com.br/revistas/read/projetos/05.056/2519>. Acesso em: 12 jun. 2017.

SERAPIÃO, F. O que aconteceu com os premiados do Opera Prima? Projeto Design, São Paulo, n. 342, 2008. Disponível em: <https://arcoweb.com.br/projetodesign/especiais/opera -prima-2008-artigo-opera-prima-20-anos-01-08-2008 >. Acesso em: 9 abr. 2017. 
SESC GUARULHOS. Concurso de propostas arquitetônicas. Portal Vitruvius, São Paulo, ano 10, n. 109.03, jan. 2010. Disponível em: <http://www.vitruvius.com.br/revistas/read/projetos/10.109/3558>. Acesso em: 13 jan. 2010.

TEATRO DE NATAL - Concurso Público Nacional de Arquitetura. Portal Vitruvius, São Paulo, ano 5, n. 059.03, jun. 2010. Disponível em: <http://www.vitruvius.com.br/revistas/read/projetos/05.059/2560>. Acesso em: 13 jun. 2010.

UNIVERSIDADE PRESBITERIANA MACKENZIE. Faculdade de Arquitetura e Urbanismo. Regulamento do Trabalho Final de Graduação, TFG. São Paulo: FAU-Mackenzie, 2001. Disponível em <http://up.mackenzie.br/fileadmin/user_upload/_imported/fileadmin/PUBLIC/ UP_MACKENZIE/servicos_educacionais/graduacao/Arquitetura_Urban_SP/REGULAMENTO_ DO_TFG___FAU_-_ATO_REITORIA_14_-_ANEXO.pdf>. Acesso em: 12 jul. 2017.

WIENFELD, I. Edifício La Petite Afrique. 2017. Disponível em: <http://isayweinfeld.com/projects/edificio-la-petite-afrique/>. Acesso em: 14 jul. 2017.

ZUMTHOR, P.; GRABOW, A. Pensar a arquitectura. Barcelona: G. Gili, 2005. 
1953. Turmas do $1^{\circ}, 2^{\circ}, 3^{\circ}, 4^{\circ}$ e $5^{\circ}$ anos de Arquitetura.

\section{No cartaz:}

Futuros Arquitetos! A nova diretoria do

Dafam será eleita na próxima sexta-

- feira, dia 30. Os candidatos deverão

fazer suas inscrições até quinta-feira,

dia 29, impreterivelmente. Colegas,

cooperem conosco.

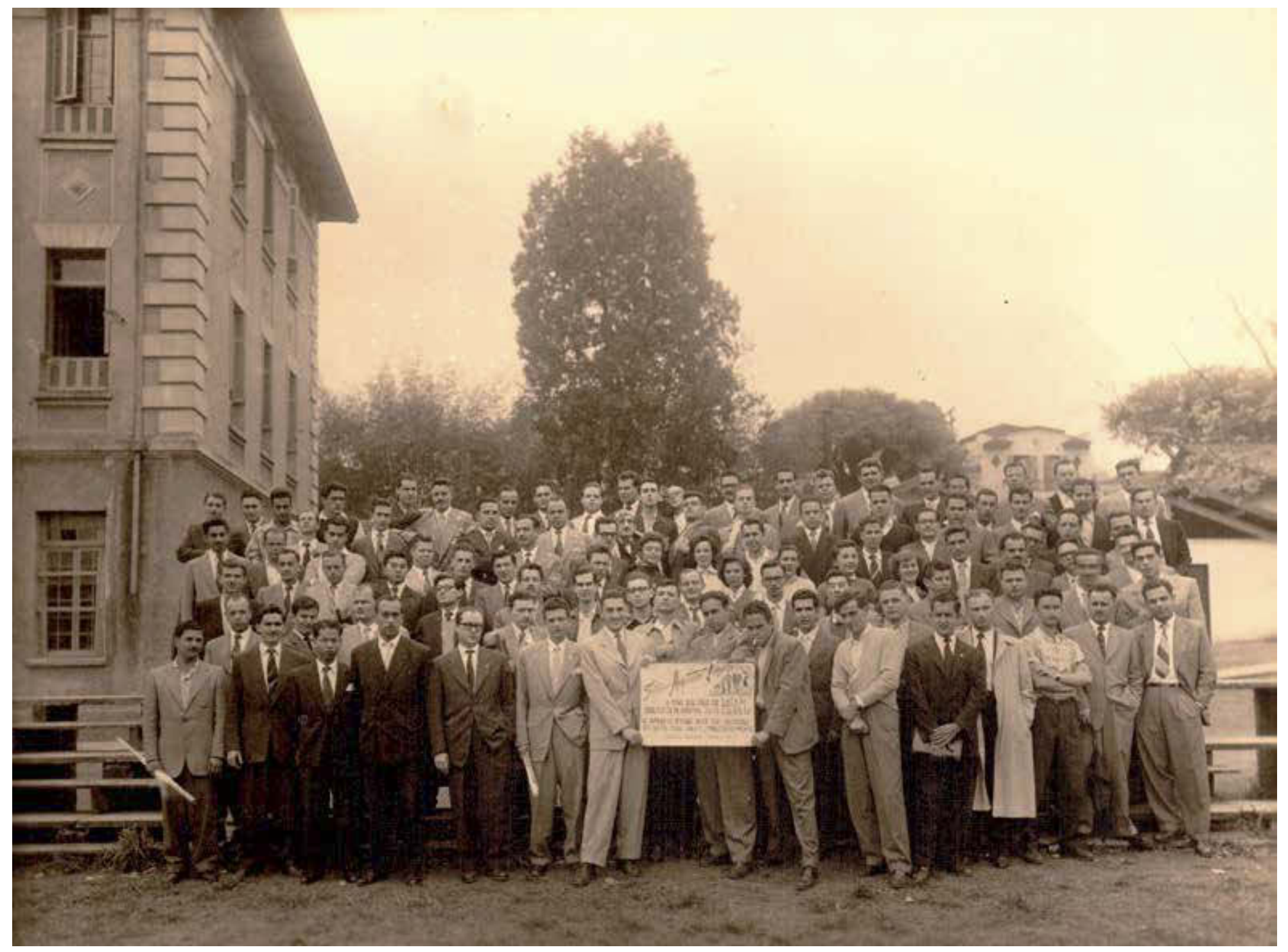

